El derecho a un juzgamiento especializado de los jóvenes infractores en el derecho internacional de los derechos humanos y su impacto en el diseño del proceso penal juvenil.

Mauricio Duce J.

páginas $73-120$

\title{
EL DERECHO A UN JUZGAMIENTO ESPECIALIZADO DE LOS JÓVENES INFRACTORES EN EL DERECHO INTERNACIONAL DE LOS DERECHOS HUMANOS Y SU IMPACTO EN EL DISEÑO DEL PROCESO PENAL JUVENIL *
}

Mauricio Duce J.**

\begin{abstract}
RESUMEN
El presente trabajo tiene por objeto identificar y analizar los principales criterios y estándares desarrollados en el ámbito del derecho internacional de los derechos humanos que marcan los alcances del derecho a un tratamiento especial en el juzgamiento por infracciones a la ley penal de los niños y jóvenes respecto de los adultos. El trabajo identifica las consecuencias concretas que tiene la necesidad de un juzgamiento especializado de jóvenes en la regulación de instituciones y garantías procesales establecidas en favor de ellos y luego determina el cómo han sido recogidas y desarrolladas por la legislación, doctrina y jurisprudencia internacional. El trabajo analiza primero la forma en que este derecho es reconocido en el sistema internacional de derechos humanos concluyendo que tiene un amplio reconocimiento. Luego se sostiene que ese derecho exige diferencias respecto al tratamiento de adultos que pueden ser sistematizadas en tres ejes que son objeto de revisión en detalle: reforzamiento del debido proceso; aspectos de estructura procesal; $y$, necesidad de contar una política amplia de diversificación de respuestas y desestimación de casos.
\end{abstract}

* Este texto corresponde a un producto de trabajo desarrollado en el contexto del proyecto Fondecyt $\mathrm{n}^{\circ} 1080644$ denominado "El Principio de Especialidad en el Derecho Penal y Procesal Penal de Adolescentes. Análisis Dogmático y Jurisprudencial" adjudicado para el período comprendido entre los años 2008-2010. En dicho proyecto tengo la calidad de co-investigador, correspondiendo al profesor Jaime Couso la calidad de investigador responsable. Quiero agradecer el valioso apoyo de investigación para la elaboración de este trabajo realizado por la ayudante del proyecto Andrea Collell. Trabajo recibido el 20 de abril de 2009 y aprobado el 29 de mayo del señalado año.

** El autor es Abogado y Master en Ciencias Jurídicas de la Universidad de Stanford. Profesor de la Facultad de Derecho de la Universidad Diego Portales. Correo electrónico: mauricio.duce@udp.cl 


\begin{abstract}
The objective of the paper is to identify and analyze the main criteria and standards developed by the International Human Rights Law regarding the right of the juveniles to be judged by a specialize system in criminal cases in comparison with the prosecution of crimes committed by adults. The paper identify the concrete consequences that this right has in the design of statutes that regulates institutions and procedural guarantees in favor of juvenile offenders and studies the way in which they have been treated and developed by the international human right law, the case law of the international courts and the opinions of international experts. The paper first presents the way in which this right has been recognized by the international human right law concluding that this right has been broadly recognized in that legislation. After that, the paper argues that this right demands differences in the criminal procedure of juvenile offenders in three main axes: strengthening of due process guarantees; aspects of procedural structure, and necessity of having a broad policy of diversion of cases.
\end{abstract}

PALABRAS CLAVES

Proceso Penal Juvenil, Derecho Internacional de los Derechos Humanos, Juzgamiento Especializado.

\title{
KEY WORDS
}

Juvenile Criminal Procedure, International Human Rights Law, Specialized Judgment

\section{1.- Introducción:}

Desde junio de 2007 ha comenzado a regir en nuestro país un nuevo sistema de responsabilidad de los adolescentes (jóvenes de entre 14 y 17 años de edad) por infracciones a la ley penal. ${ }^{1}$ Dicho sistema fue establecido con el propósito, entre otros, de satisfacer las exigencias impuestas por los tratados internacionales de derechos humanos en la materia, especialmente por la Convención de Derechos del Niño (en adelante la "Convención" o la $\mathrm{CDN}) .{ }^{2}$ Se trata de un sistema que cambió de manera radical la lógica o paradigma del sistema

Véase Ley no 20.084 , Publicada en el Diario Oficial el 7 de diciembre de 2005 y sus posteriores modificaciones (Leyes $\mathrm{n}^{\circ} 20.110 \mathrm{y} \mathrm{n}^{\circ} 20.191$ ).

2 Así, el Mensaje del Presidente de la República cuando se envía el proyecto al Congreso el año 2002 indica "Desde un punto de vista jurídico, esta reforma se fundamenta en que la actual legislación de menores, en no pocas materias, entra en contradicción con las disposiciones de la Constitución y de la Convención Internacional sobre los Derechos del Niño y, en algunos casos, directamente vulneran estos cuerpos jurídicos". Véase Mensaje de S.E. El Presidente de la República con el que inicia un proyecto de ley que establece un sistema de responsabilidad de los adolescentes por infracciones a la ley penal, 2 de agosto de 2002 (presentado ante la Cámara de Diputados). 
El derecho a un juzgamiento especializado de los jóvenes infractores en el derecho internacional de los derechos humanos y su impacto en el diseño del proceso penal juvenil.

que regía previamente y que, por lo mismo, enfrenta como uno de sus grandes desafíos el producir un cambio real respecto del tratamiento de jóvenes infractores de la ley penal. ${ }^{3}$

Hoy existe un consenso amplio respecto a que el punto de partida básico en la configuración de un sistema de justicia juvenil está en la necesidad que el juzgamiento y sanción de los niños y jóvenes por infracciones de carácter penal sean llevados adelante por un sistema especial de responsabilidad que cuente con algunas características diversas a la de los adultos. ${ }^{4}$ Este tratamiento especial se basaría en las diferencias de hecho que presentan los niños y jóvenes respecto a los adultos, lo que justificaría que los ordenamientos jurídicos establezcan reglas especiales a favor de los primeros. Así, por ejemplo, uno de los teóricos más influyentes en la materia ha señalado sobre este punto que: "El ordenamiento jurídico tiene que otorgarle un estatus especial normativo a los menores y menores adultos que se encuentran en el período de desarrollo respecto de los mayores...ello resulta ya del hecho que la gente joven muestra una menor competencia de acción (social) y un déficit de estatus social condicionado por la edad...de ello se siguen consecuencias para el procedimiento penal de menores. Esto es, menor competencia de acción significa justamente para la criminalización de gente joven, que "ellos", en el transcurso ulterior de la persecución penal, dominan poco las situaciones de interacción, pues oponen menos resistencia a las instancias... Las consecuencias de estos conocimientos de investigación instancial y criminológica de menores tienen que ser un fortalecimiento de los derechos procesales de protección en el procedimiento penal de menores". 5

Cabe señalar que la necesidad de este tratamiento diferenciado no sólo abarca las normas de procedimiento establecidas para determinar la responsabilidad de los jóvenes infractores sino que también a las normas sustantivas que establecen la responsabilidad de ellos y sus consecuencias.

La idea de que el juzgamiento a jóvenes infractores debe ser especializado ha sido recogida y consagrada como un derecho fundamental por el derecho internacional de los derechos humanos. ${ }^{6}$ En este marco de análisis, el presente trabajo tiene por objeto identificar y analizar los principales criterios y estándares desarrollados en el ámbito del derecho internacional de los derechos humanos que marcan los alcances del derecho a un tratamiento especial en el juzgamiento por infracciones a la ley penal de los niños y jóvenes respecto de los

Una revisión sistemática de los principales aspectos de la nueva ley puede verse en Bustos, Juan, Derecho Penal del Niño-Adolescente. Ediciones Jurídicas de Santiago, Santiago, 2007. En lo sucesivo utilizaré la palabra "niño" o "joven" indistintamente para referirme a los usuarios del sistema.

4 Entre otros véase Maldonado, Francisco, "La Especialidad del Sistema de Responsabilidad de Adolescentes", en Justicia y Derechos del Niño $n^{\circ}$ 9, Santiago, 2004, pp. 103 y siguientes.

Véase Albrecht, Peter-Alexis, El Derecho Penal de Menores, PPU, Barcelona, 1990, pp. 406 y 407.

Véase supra 2. 
adultos. ${ }^{7}$ Este derecho a un tratamiento especial será denominado como "principio de especialidad". Se intentará identificar, entonces, las consecuencias concretas que tiene el principio de especialidad en la regulación de instituciones y garantías procesales establecidas en favor de los jóvenes y luego determinar el cómo ellas han sido recogidas y desarrolladas por la doctrina, legislación y jurisprudencia internacional. La idea es que este trabajo permitirá luego, en una futura etapa de este proyecto, identificar la forma en que dichos estándares especiales han sido recogidos en la legislación y jurisprudencia comparada para finalmente contrastar dichos desarrollos con lo ocurrido en la nueva legislación y jurisprudencia nacional a partir de la entrada en vigencia del nuevo sistema en junio de $2007 .{ }^{8}$ En definitiva, el esfuerzo de este trabajo será el de precisar y dotar de sentidos concretos al derecho a un juzgamiento especializado de los jóvenes infractores de leyes penales en un escenario en donde la falta de claridad de los alcances de este derecho ha permitido que, no obstante se haya avanzado con reformas en diversos países de América Latina, muchas de éstas no hayan sido capaces de introducir transformaciones reales consistentes con los valores de la CDN. ${ }^{9}$

No será parte de este trabajo el análisis del impacto que debiera tener el principio de especialidad a nivel de las reglas que regulan el "derecho penal sustantivo" ni tampoco en los aspectos de diseño orgánico del sistema de justicia juvenil por infracciones a la ley penal. ${ }^{10}$

Cabe destacar que para los efectos de este trabajo utilizaré una noción amplia del derecho internacional de los derechos humanos, incluyendo como parte del mismo no sólo a los tratados internacionales, sino que la jurisprudencia de los órganos encargados de su aplicación, las opiniones de los mismos y el conjunto de resoluciones o declaraciones emanadas de organismos internacionales que son relevantes en nuestra materia de estudio. Si bien el peso normativo de los tratados internacionales es mayor que la del resto de las fuentes que utilizaré, todas ellas forman parte de un corpus que integra al derecho internacional de los derechos humanos siendo fuentes legítimas para su creación y, por cierto, con una enorme influencia en su aplicación. En esta dirección, la Corte Interamericana de Derechos Humanos ha establecido que "el corpus juris del Derecho Internacional de los Derechos Humanos está formado por un conjunto de instrumentos internacionales de contenidos y efectos jurídicos distintos (tratados, convenios, resoluciones y declaraciones), así como las decisiones adoptadas por los órganos internacionales. Su evolución dinámica ha ejercido un impacto positivo en el derecho internacional, en el sentido de afirmar y desarrollar la aptitud de este último para regular las relaciones entre los Estados y los seres humanos bajo sus respectivas jurisdicciones". Véase Corte Interamericana de Derechos Humanos, Opinión Consultiva n 16 (OC-16/99). El Derecho a la Información sobre la Asistencia Consular en el Marco de las Garantías del Debido Proceso Legal, de 1 de octubre de 1999, párrafo 115.

Esta idea también ha sido recogida por la doctrina sobre la materia. Véase Medina, Cecilia, "El Derecho Internacional de los Derechos Humanos y el Ordenamiento Jurídico Chileno", en Constitución Tratados y Derechos Esenciales, Corporación Nacional de Reparación y Reconciliación, Santiago, 1994, pp. 6 a 8. En este mismo sentido pero refiriéndose de manera específica a los instrumentos internacionales en materia juvenil véase Beloff, Mary, "Los Nuevos Sistemas de Justicia Juvenil en América Latina (1999-2006)", en Justicia y Derechos del Niño $n^{\circ} 8$, Santiago, 2006, pp. 12 y 13.

8 Sobre algunos de estos temas existe abundante bibliografía en el ámbito comparado. En este trabajo me focalizaré en la revisión de las fuentes referidas al derecho internacional de los derechos humanos.

$9 \quad$ En este sentido véase Beloff, Mary, "Los nuevos", cit. nota n. 9, p. 10.

10 La razón de no abordar los aspectos orgánicos se debe a que esta dimensión del principio de especialidad lleva al análisis de los más diversos tipos de arreglos institucionales, tanto respecto a la forma de organizar a las 
El derecho a un juzgamiento especializado de los jóvenes infractores en el derecho internacional de los derechos humanos y su impacto en el diseño del proceso penal juvenil.

Para cumplir con sus objetivos, el trabajo se dividirá, además de esta introducción (1), en cuatro capítulos y unas breves consideraciones finales. El capítulo 2 estará destinado a analizar la forma en que el "principio de especialidad" ha sido recogido en el sistema internacional de los derechos humanos. Los capítulos 3, 4 y 5 en cambio estarán destinados a revisar las principales consecuencias de ello en materia procesal. El principio especialidad del sistema de responsabilidad de adolescentes en materia procesal penal exige diferencias respecto al tratamiento de adultos que en mi opinión pueden ser sistematizadas en tres ejes que serán objeto de revisión en este trabajo en capítulos separados: reforzamiento del debido proceso respecto de los adultos (3); aspectos de estructura procesal (4); y, necesidad de contar una política amplia de diversificación de respuestas y desestimación de casos (5). El trabajo concluirá con unas breves consideraciones finales (6).

\section{2.- El Reconocimiento del Derecho de los Jóvenes a ser Juzgados en Un Sistema Especializado en el Sistema Internacional de los Derechos Humanos}

Una revisión general del derecho internacional de los derechos humanos permite concluir que el derecho a un juzgamiento especializado de los jóvenes -o como lo he llamado para efectos de este trabajo el "principio de especialidad"- encuentra una fuerte regulación y reconocimiento tanto en los instrumentos internacionales especializados en materia de infancia como en los generales, ya sea universales o de carácter regional. Asimismo, diversos órganos internacionales que aplican dichos instrumentos se han pronunciado reforzando la necesidad de la especialidad del sistema juvenil en materia procesal.

En materia de instrumentos especializados es necesario iniciar el análisis con el instrumento universal base como lo es la Convención de los Derechos del Niño. La CDN establece desde su preámbulo la idea de la necesidad de un tratamiento especial de los jóvenes y niños infractores. Así, en su párrafo noveno, haciendo referencia a la Declaración de los Derechos del Niño, señala que "el niño, por su falta de madurez física y mental, necesita de protección y cuidados especiales, incluso la debida protección legal, tanto antes como después del nacimiento". Esta idea luego se desarrolla explícitamente en el artículo 40.3 del mismo texto que establece la obligación de los Estados Partes de adoptar medidas apropiadas para promover el "....establecimiento de leyes, procedimientos, autoridades e instituciones específicos

instituciones que integran al sistema de justicia, como en sus sistemas de capacitación y entrenamiento, selección de personal, entre otras múltiples variables que nos alejan de los aspectos en los que más directamente recae la legislación procesal propiamente tal y sobre los cuales se pronuncia la jurisprudencia. Con todo, me parece indispensable dejar en claro que dicha dimensión es esencial para el cumplimiento adecuado tanto de los aspectos procesales como los substantivos del principio de especialidad. Esta opción no significa, en todo caso, que algunas cuestiones que revisaré en el presente texto no tengan un impacto en aspectos orgánicos del sistema, sino simplemente que el enfoque del trabajo no es abordar desde un punto de vista orgánico las consecuencias del derecho de los jóvenes a ser juzgado en un sistema especializado. 
para los niños de quienes se alegue han infringido las leyes penales...". ${ }^{11}$

Este mandato ha sido reforzado por la opinión que sobre la materia ha elaborado el Comité de Derechos del Niño. ${ }^{12}$ Este ha señalado recientemente en su Observación General n ${ }^{\circ} 10$ de enero/febrero del año 2007 (en adelante OG/10) referida precisamente a "Los Derechos del Niño en la Justicia de Menores" que "Los niños se diferencian de los adultos tanto en su desarrollo físico y psicológico como en sus necesidades emocionales y educativas. Estas diferencias constituyen la base de la menor culpabilidad de los niños que tienen conflictos con la justicia. Estas y otras diferencias justifican la existencia separada de justicia de menores y hacen necesario dar un trato diferente a los niños."13

No se trata del único instrumento internacional especializado que se refieren a la materia. Así, una regla similar a la de la CDN puede encontrarse en las Reglas Mínimas de Naciones Unidas para la Administración de la Justicia de Menores (en adelante "Reglas de Beijing"), que señala en su regla n ${ }^{\circ} 2.3$ "En cada jurisdicción nacional se procurará un conjunto de leyes, normas y disposiciones aplicables específicamente a los menores delincuentes, así como a los órganos e instituciones encargados de las funciones de administración de justicia de menores...." También en las Directrices de Naciones Unidas para la Prevención de la Delincuencia Juvenil (conocidas como las Directrices RIAD) de 1990 es posible encontrar una norma similar. Así, en el capítulo VI sobre legislación y administración de la justicia de menores la Directriz 52 señala "Los gobiernos deberán promulgar y publicar leyes y procedimientos especiales para fomentar y proteger los derechos y bienestar de los jóvenes".

Se puede observar que en este conjunto de instrumentos se recoge con fuerza el derecho a un juzgamiento especializado. Esta idea se basa en el reconocimiento de diferencias tanto a nivel de desarrollo físico como psicológico, aún cuando estos instrumentos no explican con detalle el alcance de dichas diferencias. ${ }^{14}$

Se podría pensar que este reconocimiento amplio obedece precisamente al carácter

11 Los principales debates e ideas discutidas en la redacción de la CDN pueden verse en Office of the United Nations High Commissioner for Human Rights, Legislative History of the Convention on the Rights of the Chile, United Nations, New York and Geneva, 2007. Sobre el artículo 40 véase el volumen II, especialmente pp. 738 a 774.

12 El Comité de los Derechos del Niño es un órgano dependiente de la Organización de Naciones Unidas creado bajo el alero de la Convención sobre los Derechos del Niño con la función de supervisar y verificar su cumplimiento de parte de los Estados signatarios.

13 Véase Comité de los Derechos del Niño, Observación General n 10, Enero/Febrero de 2007, párrafo 10 (en adelante $\mathrm{OG} / 10)$.

14 Otro trabajo que se elaborará en el contexto de este proyecto Fondecyt abordará con detalle el estado de la discusión acerca de las diferencias de los jóvenes respecto de los adultos en el debate criminológico y en la psicología del desarrollo. 
El derecho a un juzgamiento especializado de los jóvenes infractores en el derecho internacional de los derechos humanos y su impacto en el diseño del proceso penal juvenil.

especializado de los instrumentos revisados que hacen que, en alguna medida, estén forzados a marcar diferencias con instrumentos internacionales de carácter general para justificar su existencia. Es decir, al tratarse de instrumentos de orden temático específicos, referidos precisamente a la regulación de la situación de niños y jóvenes con el sistema de justicia, es natural que se reclame para ellos un tratamiento especial o distinto, aún cuando eso no constituya un principio o derecho internacional general. Sin embargo, una revisión de instrumentos generales que se refieren a la materia permite identificar que se trata de un derecho reconocido en ese nivel también con la misma fuerza.

Así, el Pacto Internacional de Derechos Civiles y Políticos (en adelante el "Pacto Internacional" o el "Pacto"), el principal tratado internacional de reconocimiento de derechos de carácter universal, establece explícitamente en su artículo 14.4, referido a las garantías del debido proceso, que " 4 . En el procedimiento aplicable a los menores de edad a efectos penales se tendrá en cuenta esta circunstancia y la importancia de estimular su readaptación social". ${ }^{15}$ A partir de esta norma el Comité de Derechos Humanos del Pacto Internacional (órgano que interpreta y aplica las disposiciones del Pacto) ha reconocido la necesidad que los procesos para el establecimiento de responsabilidad penal de los jóvenes sean conducidos de manera diferente a la de los adultos tomando en consideración sus características especiales. ${ }^{16}$ Esto ha llevado a que se sostenga que el Pacto impone en ciertas circunstancias garantías extras en favor de los jóvenes en comparación con los adultos en los procesos juveniles. ${ }^{17}$

En nuestro ámbito regional, el instrumento de mayor relevancia está constituido por la Convención Americana Sobre Derechos Humanos conocida como el Pacto de San José de Costa Rica (en adelante "Convención Americana"). ${ }^{18}$ Ella establece en su artículo 5.5 que "Cuando los menores puedan ser procesados, deben ser separados de los adultos y llevados ante tribunales especializados, con la mayor celeridad posible, para su tratamiento". ${ }^{19}$ Junto con este reconocimiento normativo explícito la Corte Interamericana de Derechos Humanos ha tenido oportunidad de pronunciarse sobre la materia, tanto como parte de su competencia consultiva como en uso de sus facultades jurisdiccionales. La Corte elaboró la Opinión Consultiva $\mathrm{n}^{\mathrm{o}} 17$ del año 2002 (en adelante OC-17/2002) cuyo tema central fue "Condición

15 Recordemos que el Pacto ha sido ratificado por Chile e incorporado a la legislación interna mediante su publicación en el Diario Oficial el día 29 de abril de 1989.

16 Véase Manfred, Nowak, U.N Covenant on Civil and Political Rights CCPR Commentary, N.P. Engel Publisher, Germany, 2005, p. 347.

17 Véase McGoldrick, Dominic, The Human Rights Comitte, Clarendon Press, Oxford, 1996, p. 411.

18 La Convención ha sido incorporada a la legislación interna por medio de su publicación en el Diario Oficial el 5 de enero de 1991.

19 Cabe señalar que una norma prácticamente idéntica está recogida en el artículo 10.2 b) del Pacto. 
Jurídica y Derechos Humanos del Niño"20 . En ella señaló que los niños: "En razón de su inmadurez y vulnerabilidad, requieren protección que garantice el ejercicio de sus derechos dentro de la familia, de la sociedad y con respecto al Estado." 21 La Corte agregó, además, que "Es evidente que las condiciones en las que participa un niño en un proceso no son las mismas en que lo hace un adulto. Si se sostuviera otra cosa se desconocería la realidad y se omitiría la adopción de medidas especiales para la protección de los niños, con grave perjuicio para estos mismos. Por lo tanto, es indispensable reconocer y respetar las diferencias de trato que corresponden a diferencias de situación, entre quienes participan en un procedimiento". ${ }^{22} 23$

Conceptos similares han sido reiterados con posterioridad por parte de la Corte Interamericana a propósito del conocimiento de casos en materias propias de sus facultades jurisdiccionales. Uno de los casos más paradigmático ha sido el caso "Instituto de Reeducación del Menor vs. Paraguay” del año 2004. ${ }^{24}$ En el párrafo 209 la Corte, citando a su OC-17/2002, señala que "Si bien los derechos procesales y sus correlativas garantías son aplicables a todas las personas, en el caso de los niños el ejercicio de aquéllos supone, por las condiciones especiales en que se encuentran los niños, la adopción de ciertas medidas específicas con el propósito que gocen efectivamente de dichos derechos y garantías". ${ }^{25}$

20 Se trata de una opinión solicitada por la Comisión Interamericana de Derechos Humanos el 30 de marzo de 2001. La solicitud busca que la Corte se pronuncie "sobre la interpretación de los artículos 8 y 25 de la Convención Americana, con el propósito de determinar si las medidas especiales establecidas en el artículo 19 de la misma Convención constituyen "límites al arbitrio o a la discrecionalidad de los Estados" en relación a niños, y asimismo solicitó la formulación de criterios generales válidos sobre la materia dentro del marco de la Convención Americana". Según se consigna en la opinión de la Corte, la preocupación de la Comisión por el tema tiene como antecedente que: "[e]n distintas legislaciones y prácticas de los países americanos, la vigencia de los derechos y garantías reconocidos en los artículos 8 y 25 por la Convención Americana no es plena respecto a los niños como sujetos y actores en jurisdicción penal, civil y administrativa, por asumirse que la obligación de protección por el Estado para suplir la falta de plenitud de juicio de los menores, puede hacer pasar a segundo plano dichas garantías. Eso implica que los derechos de los menores de edad a las garantías judiciales y a la protección judicial pueden ser menoscabados o restringidos. Por ende también otros derechos reconocidos cuya vigencia depende de la efectividad de las garantías judiciales como los derechos a la integridad personal, a la libertad personal, a la protección de la honra y la dignidad, y a la protección de la familia." Véase Corte Interamericana de Derechos Humanos, Opinión Consultiva nº 17 (OC-17/2002) Condición Jurídica y Derechos Humanos del Niño, de 28 de agosto de 2002, párrafos 1 y 2.

$21 \quad$ Idem párrafo 93.

22 Idem párrafo 96.

23 Una visión crítica y análisis detallado de la OC-17/2002 puede verse en Beloff, Mary, Luces y Sombras de la Opinión Consultiva 17 de la Corte Interamericana de Derechos Humanos: "Condición Jurídica y Derechos Humanos del Niño", en Justicia y Derechos del Niño no 4, Santiago, 2004, pp. 27 a 101.

$24 \quad$ Véase Sentencia de la Corte Interamericana de Derechos Humanos de 2 de septiembre de 2004.

25 Una visión panorámica con el conjunto de casos resueltos por el sistema interamericano de protección de derechos humanos (Corte y Comisión) actualizada al año 2009 puede verse en Comisión Interamericana de Derechos Humanos, La Infancia y Sus Derechos en el Sistema Interamericano de Protección de Derechos Humanos (segunda edición), Secretaría General de la Organización de Estados Americanos, Washington, 2009, 62 páginas (incluye CD con materiales completos). 
El derecho a un juzgamiento especializado de los jóvenes infractores en el derecho internacional de los derechos humanos y su impacto en el diseño del proceso penal juvenil.

Luego de revisado este conjunto de normas y opiniones emanadas en distintos órganos del sistema internacional me parece que es pacífico concluir acerca del reconocimiento y existencia del derecho a un juzgamiento especial de los jóvenes y la importancia que este tiene como guía para la construcción y análisis de los sistemas de justicia juvenil. En mi opinión, es claro que el principio de especialidad recogido en la legislación internacional de los derechos humanos alude a dos dimensiones diversas en materia procesal. Por una parte, al hecho que las reglas que regulen la intervención estatal en contra de jóvenes infractores deben ser específicas para ellos (es decir no deben estar sometidos exclusivamente a las reglas generales de juzgamiento de los adultos) y, en segundo lugar, deben ser aplicadas por instituciones y personas especializadas. ${ }^{26}$ Como ya señalaba esta segunda dimensión, que tiene un alto impacto en el diseño orgánico del sistema, no será objeto de desarrollo en este trabajo.

El gran desafío que impone el sistema internacional a los ordenamientos jurídicos internos es recoger estos mandatos pero sin que necesariamente exista una guía completamente desarrollada de cómo debe hacerse este proceso. La lógica general del sistema internacional de derechos humanos es regular un conjunto de normas y principios generales, entregándole un margen de apreciación a los Estados para decidir luego cómo pueden incorporar estas normas y principios generales en sus propios ordenamientos. ${ }^{27}$ En los capítulos que siguen revisaremos con mayor especificidad cuáles son estos principios generales consagrados en la legislación y jurisprudencia internacional. Como adelantaba en la introducción, me parece que este principio general puede ser bajado a tres áreas o ejes específicos que serán revisadas en los próximos capítulos. En cada uno de ellos explicaré en qué sentido la legislación internacional recoge el principio de especialidad y qué proyecciones básicas debiera tener esto en el diseño procesal de las legislaciones internas. Cabe señalar que la organización del trabajo en tres áreas deja sin análisis algunas manifestaciones o alcances específicos del derecho a un juzgamiento especializado en materia procesal que sistemáticamente no caben debajo de ninguna de las categorías en análisis. En consecuencia, no se trata de un trabajo que tenga la aspiración de cubrir todas las posibles manifestaciones del principio de especialidad, sino de aquellas que me parecen más relevantes por representar diferencias en las estructuras procesales más significativas del sistema.

26 Con claridad distinguiendo entre estas dos dimensiones puede verse el párrafo 210 de la sentencia de la Corte Interamericana de Derechos Humanos de 2 de septiembre de 2004, en él, citando nuevamente la OC-17/2002 se señala que "Este Tribunal ha sostenido que una consecuencia evidente de la pertinencia de atender en forma diferenciada y específica las cuestiones referentes a los niños, y particularmente, las relacionadas con la conducta ilícita, es el establecimiento de órganos jurisdiccionales especializados para el conocimiento de conductas penalmente típicas atribuidas a aquéllos y un procedimiento especial por el cual se conozcan estas infracciones a la ley penal".

27 En este sentido, el artículo $4^{\circ}$ de la CDN señala que "Los Estados Partes adoptarán todas las medidas administrativas, legislativas y de otra índole para dar efectividad a los derechos reconocidos en la presente Convención" 


\section{3.- Primer Eje: Reforzamiento del Debido Proceso}

Un primer eje temático en donde el principio de especialidad tiene un impacto relevante en materia procesal penal es en el reforzamiento de ciertas garantías que integran al debido proceso. Esto supone que nos detengamos brevemente primero en el piso básico de lo que se garantiza a los jóvenes y luego se avance a ver algunos aspectos específicos que se derivan de su especial condición.

Hoy me parece pacífica la idea que la construcción de cualquier sistema procesal se debe hacer sobre la base de respetar las garantías mínimas del debido proceso. El supuesto básico en la legislación internacional para la existencia de un proceso legítimo es el debido proceso $^{28}$, el cual se encuentra ampliamente regulado tanto en el Pacto Internacional (fundamentalmente artículos 9 y 14) y tratados regionales como la Convención Americana (fundamentalmente artículos 7 y 8) y el Convenio Europeo de Derechos Humanos (artículos 5 y 6). ${ }^{29}$ Una característica central de la noción del debido proceso reconocida en el sistema internacional, es que ésta constituye una garantía compleja, compuesta por múltiples garantías específicas, todas las cuales deben estar presentes al momento en que se determinan judicialmente derechos y obligaciones de las personas, no importado la calidad que tengan esas personas. ${ }^{30}$

En este contexto argumentar que el piso de garantías procesales para los jóvenes está constituido por el debido proceso debiera ser una cuestión obvia que ni siquiera requeriría mención. ${ }^{31}$ Con todo, la evolución histórica de los sistemas de responsabilidad juvenil da cuenta que se trata de una idea muy reciente que incluso no se ha instalado con la misma fuerza

28 En este sentido véase la opinión de la Corte Interamericana en OC-17/2002 que señala en su párrafo 115 que "Las garantías judiciales son de observancia obligatoria en todo proceso en que la libertad individual de un individuo está en juego".

29 Una visión detallada de las principales garantías penales reconocidas en el ámbito internacional, pero con especial énfasis en la jurisprudencia de la Convención Europea, puede verse en Stavros, Stephanos, The Guarantees for Accused Persons Under Article 6 of the European Convention on Human Rights, Martinus Nijhoff Publishers, Netherlands, 1993, 388 págs.; y, Trechsel, Stefan, Human Rights in Criminal Proceedings, Oxford University Press, 2006, 611 págs.

30 Esta idea es recogida, entre otras, por la Corte Interamericana que al definir el debido proceso lo ha caracterizado como un "Conjunto de condiciones que deben cumplirse para la adecuada defensa de aquellos cuyos derechos y obligaciones están bajo consideración judicial”. Véase, Corte Interamericana de Derechos Humanos, Opinión Consultiva 9/1987 (“Suspensión de las Garantías en Estados de Excepción”). Debe señalarse que la cita se refiere a la primera vez que la Corte precisó esta idea, pero luego se reproduce en prácticamente todos los fallos que se refieren al tema.

31 Maier grafica con claridad esta idea al señalar "El 'niño' o el 'jóven' es, sin discusión, una persona humana y, por lo tanto, ese reglamento básico (refiriéndose al debido proceso) es aplicable a él cuando se trata de resolver sobre limitaciones a sus derechos, sea cual fuere la excusa bajo la cual tal limitación de derechos se lleva a cabo". Maier, Julio, "Los Niños Como Titulares del Derecho al Debido Proceso", en Justicia y Derechos del Niño $n^{\circ}$ 2, Buenos Aires, 2000, p. 12 (el paréntesis es mío). 
El derecho a un juzgamiento especializado de los jóvenes infractores en el derecho internacional de los derechos humanos y su impacto en el diseño del proceso penal juvenil.

en todas las legislaciones nacionales. ${ }^{32}$ De hecho, baste recordar que la OC/17 de la Corte Interamericana surge precisamente como consecuencia de la preocupación manifestada por la Comisión Interamericana sobre este punto. En efecto, la Comisión señala en su petición a la Corte que son diversos los países del continente que desconocen la plena aplicación de las garantías procesales de la Convención Americana “...por asumirse que la obligación de protección por el Estado para suplir la falta de plenitud de juicio de los menores, puede hacer pasar a segundo plano dichas garantías..." ${ }^{33}$ Es por ello que distintos organismos internacionales se pronuncian específicamente sobre el punto, con el objeto de asentar una idea que ha estado ausente en muchas de las legislaciones sobre responsabilidad juvenil. Así, el Comité de Derechos Humanos del Pacto Internacional ha señalado en su Comentario General n 13 que a los jóvenes se les debe reconocer al menos las mismas garantías y protecciones que a los adultos contenidas en el artículo 14 del Pacto. ${ }^{34}$ La Corte Interamericana ha hecho para sí esta misma argumentación en su OC-17/2002 al citar de manera textual el párrafo respectivo del Comentario General no $13^{35}$ y luego la ha reforzado en su jurisprudencia al indicar, en un caso referido precisamente a la situación de niños infractores, que "...las garantías consagradas en el artículo 8 de la Convención se reconocen a todas las personas por igual..."36

Esta lógica general es recogida en los tratados internacionales especiales en la materia toda vez que en ellos se regula de manera muy parecida a los adultos el debido proceso. En efecto, si se comparan las normas del artículo 40 de la CDN con regulaciones como el artículo 8 de la Convención Americana y el artículo 14 del Pacto Internacional, se puede apreciar que la columna vertebral del conjunto de garantías que integran el debido proceso

32 Es sabido que en el contexto de los sistemas proteccionistas o tutelares vigentes hasta hace muy poco en la región la variable de garantías procesales de los jóvenes imputados era prácticamente inexistente. Otro caso paradigmático es lo ocurrido en la legislación y jurisprudencia de los Estados Unidos en donde a partir del famoso caso In re Gault de 1967 el gran esfuerzo jurisprudencial ha sido que los jóvenes gocen de las protecciones básicas del debido proceso largamente desarrolladas en favor de adultos y que hasta esa época eran aplicadas en favor de ellos de manera marginal. Una visión general de esta evolución puede verse en Gardner, Martin, Understanding Juvenile Law, Mathew Bender, New York, 1997, pp. 186 a 198.

33 El párrafo completo señala: "[e]n distintas legislaciones y prácticas de los países americanos, la vigencia de los derechos y garantías reconocidos en los artículos 8 y 25 por la Convención Americana no es plena respecto a los niños como sujetos y actores en jurisdicción penal, civil y administrativa, por asumirse que la obligación de protección por el Estado para suplir la falta de plenitud de juicio de los menores, puede hacer pasar a segundo plano dichas garantías. Eso implica que los derechos de los menores de edad a las garantías judiciales y a la protección judicial pueden ser menoscabados o restringidos. Por ende también otros derechos reconocidos cuya vigencia depende de la efectividad de las garantías judiciales como los derechos a la integridad personal, a la libertad personal, a la protección de la honra y la dignidad, y a la protección de la familia." Véase Corte Interamericana de Derechos Humanos, OC-17/2002 párrafo 2.

34 Véase Comité de Derechos Humanos, Comentario General n 13 de 1984, párrafo 16.

Véase OC17/2002 párrafo 100.

Véase Sentencia de la Corte Interamericana de Derechos Humanos de 2 de septiembre de 2004, párrafo 209 (caso “Instituto de Reeducación del Menor” vs. Paraguay). 
se encuentra estructurada de manera similar. ${ }^{37}$

A partir del reconocimiento de este piso básico de garantías, la pregunta relevante es esclarecer si el principio de especialidad se traduce en la legislación internacional en alguna diferencia relevante en favor de los jóvenes en términos de los alcances del debido proceso. La revisión de las normas y jurisprudencia internacional lleva a una respuesta afirmativa. Esta pasa por una exigencia del sistema internacional de reforzar los contenidos existentes en favor de los niños y jóvenes en varias áreas o materias.

Esta idea ha sido reconocida con mucha claridad por la doctrina internacional ${ }^{38}$ y especialmente en el sistema interamericano de protección de derechos humanos. La Corte ha señalado en la OC-17/2002 que “...es importante destacar que los niños poseen los derechos que corresponden a todos los seres humanos - menores y adultos- y tienen además derechos especiales derivados de su condición, a los que corresponden deberes específicos de la familia, la sociedad y el Estado". ${ }^{39}$ Específicamente en materia de garantías del debido proceso ha señalado "Si bien los derechos procesales y sus correlativas garantías son aplicables a todas las personas, en el caso de los niños el ejercicio de aquéllos supone, por las condiciones especiales en las que se encuentran los niños, la adopción de ciertas medidas específicas con el propósito de que gocen efectivamente de dichos derechos y garantías". ${ }^{40}$

Del análisis más específico de los instrumentos del sistema internacional me parece que los principales aspectos en donde el principio de especialidad se traduce en diferencias significativas de reforzamiento o ampliación de garantías del debido proceso son cuatro: El fortalecimiento de la libertad y las mayores restricciones a su privación en el proceso; exigencias más estrictas respecto a la extensión temporal del proceso; mayores resguardos al derecho de

37 Incluso se puede apreciar que la CDN perfecciona un problema de redacción que presenta la Convención Americana. En efecto, la versión en español de la CDN representa una mejor traducción que la de la Convención Americana en la garantía principal del debido proceso: el derecho a una audiencia o juicio oral. Dicha garantía está contemplada en ambos textos, pero la redacción de la CDN supera un problema que presenta la Convención. Es así como frente al mismo texto en inglés de ambas que se refiere al "right to a fair hearing" la Convención Americana lo traduce como "derecho a ser oído con las debidas garantías" y la de CDN correctamente lo hace como "derecho a una audiencia equitativa". Una discusión detallada sobre este punto y su impacto en materias de debido proceso puede verse en Duce, Mauricio y Riego, Cristián,, Proceso Penal, Editorial Jurídica de Chile, Santiago, 2007, pp. 375 a 384.

38 Véase, entre otros, Llobet, Javier, Derechos Humanos y Justicia Penal Juvenil, documento en formato electrónico en poder del autor, p. 4 y Maier, "Los Niños", cit. nota n. 33, p.. 15, en donde señala "El hecho que se admita una diferencia entre un niño y un adulto sólo autoriza a reconocerle más derechos (por ejemplo educación, familia, etc.) y no a disminuir sus derechos en relación con los adultos".

39 OC-17/2002 párrafo 54.

40 Véase Sentencia de la Corte Interamericana de Derechos Humanos de 2 de septiembre de 2004, párrafo 209 (caso "Instituto de Reeducación del Menor" vs. Paraguay), en el mismo sentido y en términos literales véase OC-17/2002 párrafo 98. 
El derecho a un juzgamiento especializado de los jóvenes infractores en el derecho internacional de los derechos humanos y su impacto en el diseño del proceso penal juvenil.

defensa (en diversas manifestaciones); y, exigencias más estrictas para la renuncia de derechos del debido proceso. A continuación revisaré cada uno de estos temas.

\section{1.- Fortalecimiento de la Libertad y Mayores Restricciones a su Privación en el Proceso}

La privación de libertad en el proceso, conocida normalmente como prisión o detención preventiva en caso de los adultos, constituye una de las afectaciones más significativas a los derechos de las personas objeto de una investigación criminal y, por lo mismo, es objeto de preocupación especial en los tratados internacionales de derechos humanos. A grandes rasgos, la legislación y jurisprudencia internacional ha establecido como principios rectores en el uso de la prisión preventiva los de excepcionalidad, proporcionalidad y necesidad de la misma. Respecto de esto último, se ha señalado especialmente que para que pueda proceder una prisión preventiva es requerido la existencia de un supuesto material (indicios de que un delito se ha cometido y que la persona imputada ha tenido algún grado de participación en el mismo) y la necesidad de cautela (una justificación específica acerca de la necesidad de la procedencia de esta medida para resguardar algún fin de cautela procesal). ${ }^{41}$ A todo lo anterior, se suma el establecimiento de límites temporales a la extensión de la prisión preventiva en caso que ésta haya sido decretada por medio de la regulación de la garantía del plazo razonable de su duración. ${ }^{42}$ Como se puede observar, se trata de un tema en que por la naturaleza de los derechos en juego ha generado importante preocupación en el ámbito del sistema internacional de derechos humanos y que es objeto permanente de revisión en la jurisprudencia internacional.

Las preocupaciones anteriores se ven intensificadas cuando se está en presencia del uso de la privación de libertad tratándose de jóvenes y niños. En efecto, el Comité de Derechos del Niño en su OG/10 señala que "El recurso a la privación de libertad tiene consecuencias muy negativas en el desarrollo armonioso del niño y dificulta gravemente su reintegración a la sociedad". ${ }^{43}$ En la misma dirección el comentario contenido en la Regla $n^{\circ} 13$ de Beijing destaca, en una frase poco feliz en mi opinión debido al lenguaje utilizado y los alcances del mismo, el peligro que tiene la privación de libertad de jóvenes debido a la posibilidad de sufrir "influencias corruptoras".

41 La revisión en detalle del alcance de estas restricciones y garantías tratándose de los adultos es algo que excede los objetivos del trabajo. Para tener una visión acabada del estado de la cuestión en el sistema internacional de derechos humanos recomiendo la revisión de una decisión relativamente reciente de la Comisión Interamericana de Derechos Humanos en donde se resume "el estado del arte" en la materia. Véase, Comisión Interamericana de derechos Humanos, Informe $n^{\circ} 35 / 07$ de $1^{\circ}$ de mayo de 2007, especialmente párrafos 68 a 94.

42 Mayor desarrollo sobre esta garantía específica véase Duce, Mauricio, "Sentencia de la Corte de Apelaciones de La Serena de 17 de febrero de 2004, Rol No 17-2004. Comentario sobre la garantía del "plazo razonable"”, Polít. crim. $\mathrm{n}^{\circ}$ 2, D3, p. 1-12.

43 OG/10 párrafo 11. 
El punto que aparece detrás de estas observaciones y comentarios es que los niños y jóvenes, por su estado de desarrollo, se encuentran en una situación de vulnerabilidad mayor que los adultos que hacen que los efectos negativos de la privación de libertad sean más profundos y tengan consecuencias que se extiendan por un período más largo en el tiempo. Es por eso que, a partir de esta idea, las reglas internacionales profundizan las exigencias para el uso de la prisión preventiva (especialmente véase el artículo 37 de la CDN y la Regla n ${ }^{\circ} 13$ de las Reglas de Beijing). ${ }^{44}$ Estas mayores exigencias se traducen en las siguientes cuestiones.

\subsection{1.- Procedencia de la Prisión Preventiva}

Una primera área en donde se produce un reforzamiento de garantías en favor de los jóvenes es en las hipótesis en que se autoriza a las legislaciones nacionales el uso de la privación de libertad durante el proceso. El sistema internacional manifiesta una clara vocación por limitar aún más respecto de los niños y jóvenes el uso de la prisión preventiva como medida cautelar en el procedimiento lo que se traduce claramente en el lenguaje utilizado por diversos instrumentos internacionales en la materia. Estos presentan algunas diferencias relevantes respecto a la forma en que el mismo tema es regulado en los tratados internacionales generales. Así, el artículo 37 b) de la CDN señala que la prisión preventiva “...sólo se utilizarán como medida de último recurso....". Un lenguaje similar es utilizado por las Reglas de Beijing al establecer en la Regla n ${ }^{\circ} 13.1$ que "Sólo se aplicará prisión preventiva como último recurso...". De una forma similar, las Reglas de Protección de Menores Privados de Libertad se refieren al punto en la regla $n^{\circ} 2$ (aún cuando se trata de una regla que abarca a toda privación de libertad incluyendo a las penas) que señala "La privación de libertad de un menor deberá decidirse como último recurso y en el período mínimo necesario y limitarse a casos excepcionales". Dicha regla es complementada luego de manera específica para el caso de la prisión preventiva por la regla n' 17 que señala que "En la medida de lo posible, deberá evitarse y limitarse a circunstancias excepcionales la detención antes del juicio. En consecuencia, deberá hacerse todo lo posible por aplicar medidas sustitutorias".

Como ya he mencionado previamente, la idea de excepcionalidad en el uso de la prisión preventiva es un principio general del derecho internacional de los derechos humanos, pero cuando se contrasta el lenguaje utilizado para expresar dicho principio en los instrumentos específicos de los jóvenes se puede notar claramente un matiz en favor de reforzar su aplicación para este grupo de personas. En efecto, el Pacto en su artículo 9.3 señala que "La prisión

A lo anterior debe sumarse una normativa especial dictada por la Organización de Naciones Unidas para lidiar con la situación de niños y jóvenes privados de libertad que incluye diversas disposiciones para la materia en análisis. Se trata de las Reglas de Naciones Unidas para la Protección de los Menores Privados de Libertad (en adelante las "Reglas de Protección de Menores Privados de Libertad"), aprobada por resolución 45/113 de la Asamblea General el 14 de diciembre de 1990. 
El derecho a un juzgamiento especializado de los jóvenes infractores en el derecho internacional de los derechos humanos y su impacto en el diseño del proceso penal juvenil.

preventiva de las personas que hayan de ser juzgadas no será la regla general, pero su libertad podrá estar subordinada a...”. En la Convención Americana, este principio es incluso formulado en un lenguaje menos fuerte al establecerse en el artículo 7.2 que la privación de libertad en los casos y condiciones previstas en las constituciones y leyes de los Estados parte y luego en el artículo 7.5 al establecer que la libertad durante el proceso puede estar "....condicionada a garantías que aseguren su comparencia a juicio".

Se puede observar sin necesidad de mayores análisis que se trata de cláusulas mucho más débiles respecto a la regulación del principio el ámbito juvenil. ${ }^{45}$ Esto tiene algunas consecuencias, como por ejemplo, que tratándose de niños y jóvenes se establece una obligación fuerte a los Estados de establecer sistemas de medidas cautelares alternativas que disminuyan el uso de la prisión preventiva que no aparece con tanta claridad en los tratados internacionales generales. En esa dirección se orienta tanto la Regla $n^{\circ} 17$ de las Reglas de Protección de Menores Privados de Libertad ya transcrita, como la Regla n ${ }^{\circ} 13.2$ de las Reglas de Beijing. ${ }^{46}$

El Comité de Derechos del Niño en su OG/10 ha reforzado dicha obligación señalando que los Estados “.... deben contemplar un conjunto de alternativas eficaces para dar cumplimiento a la obligación que les incumbe en virtud de la disposición de utilizar la prisión preventiva como último recurso" ${ }^{\prime 7}$ Esta preocupación también ha sido objeto de observaciones específicas del Comité a informes nacionales en países tan diversos como Canadá, Benin, Latvia y Omán. ${ }^{48}$ Incluso muy recientemente el Comité se ha pronunciado en el mismo sentido en su informe sobre Reino Unido e Irlanda del Norte. ${ }^{49}$

Además de lo señalado, el Comité de Derechos del Niño ha expresado que como consecuencia natural del principio en análisis los Estados “....deberán adoptar las medidas legislativas y de otro tipo que sean necesarias para limitar la utilización de la prisión preventiva". ${ }^{50}$ Idea que se ha expresado también en diversas recomendaciones del Comité a países como Mongolia, Latvia y Filipinas, entre otros. ${ }^{51}$ Esta mayor exigencia debiera traducirse

45 Esto sin perjuicio que la jurisprudencia internacional haya dotado por vía de la interpretación de dichas normas una fuerza mayor al principio de excepcionalidad que la que aparece regulada en los textos, particularmente en el caso de la Convención Americana. Que señala "Siempre que sea posible se adoptarán medidas sustitutorias de la prisión preventiva, como la supervisión estricta, la custodia permanente, la asignación a una familia o al traslado a un hogar o institución educativa".

47 OG/10 párrafo 80 (el subrayado es mío).

48 Véase, Hodgkin, Rachel and Newell, Peter, Implementation Handbook for the Convention on the Rights of the Child, Third Edition, UNICEF, p. 556.

49 Véase Comité de los Derechos del Niño, Examen de los Informes Presentados por los Estados Partes con Arreglo al Artículo 44 de la Convención: Observaciones Finales Reino Unido de Gran Bretaña e Irlanda del Norte, 20 de octubre de 2008, párrafo 78.

50 OG/10 párrafo 80 (el subrayado es mío).

51 Véase, Hodgkin, and Newell, "Implementation", cit. nota n. 51, p. 558. 
en las legislaciones nacionales en regulaciones de muy diversa naturaleza, por ejemplo en normas que establezcan casos de improcedencia de la prisión preventiva en hipótesis en que sí sería procedente tratándose de adultos (por ejemplo por monto de las penas asignadas al delito respectivo); sistemas de fianzas no monetarias especiales para los jóvenes, entre otras.

En definitiva, desde el punto de vista de las hipótesis en que el sistema internacional admite el uso de la privación de libertad en el proceso, es claro que en materia de niños y jóvenes se establecen exigencias más estrictas que se traducen en deberes adicionales de los Estados partes que tratándose de adultos. Esto no sólo debiera reflejarse en una práctica distinta de los tribunales sino en normas procesales e instituciones (por ejemplo sistemas sustitutivos) específicos orientados a reservar efectivamente el uso de la privación de la libertad en el proceso como un mecanismo de ultima ratio.

\subsection{2.- Duración o Extensión Temporal de la Prisión Preventiva}

Un segundo aspecto de la regulación de la prisión preventiva en el sistema internacional en donde se nota un reforzamiento de garantías a favor de niños y jóvenes respecto de los adultos es en relación a la garantía conocida como "plazo razonable de duración de la prisión preventiva". Es decir, en los casos en que el sistema internacional considera ilegítima una privación de libertad en el proceso por el sólo transcurso del tiempo no obstante se mantengan intactos los supuestos (legítimos) que permitieron su utilización original.

Nuevamente una revisión del lenguaje en el que se formula esta garantía arroja claras luces a favor de los niños y jóvenes. Así, el artículo 7.5 de la Convención Americana señala que "Toda persona detenida o retenida ... tendrá derecho a ser juzgada dentro de un plazo razonable o a ser puesta en libertad, sin perjuicio de que continúe el proceso". De manera similar el artículo 9.3 del Pacto señala "Toda persona detenida o presa ... tendrá derecho a ser juzgada dentro de un plazo razonable o a ser puesta en libertad". Como se puede apreciar, el énfasis de los tratados generales está en la idea de "plazo razonable" como límite a la extensión temporal de la prisión preventiva. En términos generales, la jurisprudencia internacional ha establecido, a propósito de la garantía general de ser juzgado en un plazo razonable, la imposibilidad de determinar la razonabilidad de los plazos en abstracto. En cambio, ha establecido que ella debe determinarse caso a caso por medio del análisis de tres criterios: la complejidad del caso, la conducta del acusado y el comportamiento de las autoridades estatales competentes ${ }^{52}$ En el ámbito específico de la dimensión de plazo razonable y prisión preventiva la Comisión Interamericana ha establecido una metodología de análisis que complementa este desarrollo jurisprudencial. Así, la Comisión estableció, en el caso Giménez (informe 12/96 del

\footnotetext{
52 Sobre la garantía general del derecho a ser juzgado en un plazo razonable y su desarrollo jurisprudencial en el sistema internacional de protección de los derechos humanos véase Pastor, Daniel, El Plazo Razonable en el Proceso del Estado de Derecho, Editorial Ad-Hoc, Buenos Aires, 2003.
} 
El derecho a un juzgamiento especializado de los jóvenes infractores en el derecho internacional de los derechos humanos y su impacto en el diseño del proceso penal juvenil.

1 de marzo de 1996), que para analizar la razonabilidad del plazo de detención era necesario realizar un examen de dos partes. Primero, se debía examinar la "pertinencia y suficiencia" de las justificaciones utilizadas para mantener al acusado privado de libertad y luego, solo en la medida que ello fuera satisfecho, debía revisarse si las autoridades habían procedido con "diligencia especial" en la instrucción del proceso para que el período de detención no fuera excesivo. En esta segunda parte del examen la Comisión incorpora indirectamente los tres criterios ya señalados.

La redacción de las normas específicas para niños y jóvenes presenta diferencias importantes. Así, el artículo 37 b) de la CDN establece que "La detención, encarcelamiento o la prisión de un niño se llevará a cabo...durante el período más breve que proceda". En la misma dirección la regla $\mathrm{n}^{\mathbf{0}} 13.1$ de las Reglas de Beijing señala que "Sólo se aplicará la prisión preventiva... durante el plazo más breve posible”. Lo mismo ocurre en la Regla n ${ }^{\circ} 17$ de las Reglas de Protección de Menores Privados de Libertad que señala que "Cuando, a pesar de ello, se recurra a la detención preventiva, los tribunales de menores y los órganos de investigación deberán atribuir máxima prioridad a la más rápida tramitación posible de esos casos a fin que la detención sea lo más breve posible."

Se puede observar que en los tres instrumentos internacionales específicos el énfasis está en la idea de "plazo lo más breve posible" el que resulta un lenguaje mucho más estricto que la noción más abierta de "plazo razonable", aun cuando debe reconocerse que se trata de una formulación nuevamente puesta en formato de estándar y que, por lo mismo, no impone una regla cerrada. Con todo, esta mayor estrictez de lenguaje debiera tener un impacto significativo al evaluar los casos concretos de duración de la privación de libertad, incluso utilizando los mismos criterios desarrollados para evaluar el exceso de razonabilidad del plazo por la jurisprudencia internacional. Para estos efectos, la propia jurisprudencia internacional ha señalado que junto con los tres criterios clásicos para ponderar la razonabilidad del plazo debe analizarse el nivel de afectación a la persona en concreto considerando sus características particulares $^{53}$, lo que abre la puerta para incluir las consideraciones especiales que deben tenerse presente si la privación de libertad recae en un niño o adolescente.

Se trata de una jurisprudencia muy reciente en el ámbito interamericano. Véase Sentencia de la Corte Interamericana de Derechos Humanos de 27 de Noviembre de 2008 caso Valle Jaramillo contra Colombia, párrafo 155: "La Corte ha establecido que es preciso tomar en cuenta tres elementos para determinar la razonabilidad del plazo: a) la complejidad del asunto; b) la actividad procesal del interesado, y c) la conducta de las autoridades judiciales. El Tribunal considera pertinente precisar, además, que en dicho análisis de razonabilidad se debe tomar en cuenta la afectación generada por la duración del procedimiento en la situación jurídica de la persona involucrada en el mismo, considerando, entre otros elementos, la materia objeto de la controversia. Si el paso del tiempo incide de manera relevante en la situación jurídica del individuo, resultará necesario que el procedimiento corra con más diligencia a fin de que el caso se resuelva en un tiempo breve" En todo caso, este criterio también ha sido desarrollado -hace bastante tiempo, en el sistema Europeo de Derechos Humanos. Véase Trechsel, Human, cit. nota n. 31, p. 144. 
Más allá de estas consideraciones, el propio Comité de Derechos del Niño se ha pronunciado en su OG/10 acerca de este tema en la misma dirección que he sostenido. Especialmente resulta interesante que el Comité recomienda dos tipos de acciones legislativas a los Estados parte para hacer efectivo este derecho. Por una parte, la necesidad que las leyes internas establezcan límites temporales a la duración de la prisión preventiva y, por la otra, un sistema de examen o revisión periódica de la misma. ${ }^{54}$ El Comité incluso va un poco más allá, señalando que si existe prisión preventiva deberán presentarse una imputación formal en contra del menor y ponerlo a disposición del órgano judicial a más tardar en 30 días desde decretada la prisión preventiva. Además, se recomienda adoptar disposiciones internas para que en todo caso la decisión definitiva del caso (considerando todas las instancias procesales) no supere el plazo de seis meses. ${ }^{55}$ El establecimiento de plazos máximos de duración de la prisión preventiva es un tema cada vez más común en las legislaciones procesales de adultos. Con todo, las exigencias temporales sugeridas por el Comité tienden a ser bastante más estrictas que lo que normalmente se encuentra a nivel comparado tratándose de adultos, lo que precisamente da cuenta del carácter reforzado de la garantía tratándose de jóvenes y niños. ${ }^{56}$

En materia de revisión de la prisión preventiva, el Comité sugiere a los Estados parte adoptar disposiciones jurídicas que aseguren revisión permanente y periódica de la misma, preferentemente cada dos semanas. ${ }^{57}$ Según se puede observar, se trata de una obligación bastante estricta, la que normalmente no se formula con tanta intensidad en la legislación procesal de adultos.

\subsection{3.- Condiciones de Cumplimiento de la Prisión Preventiva}

Las condiciones de cumplimiento de la prisión preventiva representan otra área en donde es posible encontrar un conjunto de garantías específicas en favor de los niños y jóvenes imputados que no se contemplan en favor de los adultos en la legislación internacional. La manifestación más clásica de esto, prácticamente reconocida en todos los instrumentos internacionales generales y específicos, es la necesidad que exista separación entre adultos y jóvenes sometidos a prisión preventiva. Así, por ejemplo, el artículo 10.2 letra b) del Pacto establece que "Los menores procesados estarán separados de los adultos...". Idea similar es

\footnotetext{
$54 \quad$ OG/10 párrafo 80.

55 OG/10 párrafo 83 .

56 A modo de ejemplo se pueden señalar algunos de los plazos contenidos en legislaciones procesales penales de América Latina. El CPP de Bolivia de 1999 establece como plazo los 18 meses hasta antes de la dictación de la sentencia y de 24 meses antes de que ésta esté ejecutoriada; el CPP de Costa Rica de 1998 establece un plazo máximo de 12 meses; el CPP de Guatemala de 1994 establece como máximo un año si que no se hubiere dictado sentencia condenatoria y en caso que sí se hubiere dictado y hubiere recurso pendiente ese plazo se amplía en tres meses más; algo similar establece el CPP de República Dominicana de 2002 pero con plazos de 18 y 24 meses respectivamente.

$57 \quad$ OG/10 párrafo 83.
} 
El derecho a un juzgamiento especializado de los jóvenes infractores en el derecho internacional de los derechos humanos y su impacto en el diseño del proceso penal juvenil.

recogida por el artículo 5.5 de la Convención Americana al sostener que "Cuando los menores puedan ser procesados, deben ser separados de los adultos...”. Tratándose de los instrumentos específicos, esta norma es reconocida en el artículo 37 letra c) inciso segundo de la CDN, como en la regla $n^{\circ} 13.4$ de las Reglas de Beijing, entre las más relevantes.

La justificación de esta norma de aceptación general tiene que ver nuevamente con el especial estado de vulnerabilidad de los jóvenes privados de libertad. Con ella se intenta impedir cualquier tipo de influencia negativa que podría representar el contacto de los jóvenes con adultos encarcelados. ${ }^{58}$ De hecho, el Comité de Derechos del Niño señala en su OG/10 al respecto que existe mucha evidencia acerca del efecto negativo que produce la internación de jóvenes con adultos en un mismo recinto, tanto para su seguridad y bienestar como para su capacidad futura de no reincidencia y de reintegración social. ${ }^{59}$

Existe algún debate acerca del carácter absoluto o no de esta norma de separación, particularmente en el ámbito de los tratados generales de derechos humanos. Así, alguna doctrina internacional discute la conveniencia de entender dicha norma sin flexibilidad alguna identificando casos en donde la mezcla entre jóvenes y adultos (por ejemplo de una niña con una madre joven) incluso podría ser beneficiosa a los fines de la legislación internacional. ${ }^{60}$ En todo caso, este debate pareciera estar superado en los instrumentos especiales ya que la propia CDN se encarga de reconocer una excepción a la regla de separación en el artículo 37 b) al señalar “... a menos que ello se considere contrario al interés superior del niño...” Cláusula que, en todo caso, de acuerdo al Comité de Derechos del Niño debe interpretarse restrictivamente y siempre en interés del niño y no en el sentido que sea conveniente a los Estados partes. ${ }^{61}$

De la mano de la separación, otra preocupación muy importante del sistema internacional es que las condiciones de la privación de libertad se hagan con pleno respeto y reconocimiento de los derechos del niño o joven encarcelado. El artículo 37 c) de la CDN, la Regla n ${ }^{\circ} 13.3$ de las Reglas de Beijing y la Regla $n^{\circ} 18$ de las Reglas de Protección de Menores Privados de Libertad, entre otras, se encargan de explicitar esta idea, especialmente destacando la necesidad de que los jóvenes cuenten con asesoramiento letrado y contacto permanente con su familia. ${ }^{62}$

En este sentido véase el comentario a la Regla n 13 de las Reglas de Beijing en donde incluso se va un poco más allá de la regla en análisis al sostenerse que "Las diversas características físicas y psicológicas de los jóvenes reclusos pueden justificar medidas de clasificación por las que algunos de ellos estén recluidos aparte mientras se encuentran en prisión preventiva, lo que contribuye a evitar que se conviertan en víctimas de otros reclusos y permite prestarles una asistencia más adecuada"

OG/10 párrafo 85 .

Véase Trechsel, Human, cit. nota n. 31, p. 447.

OG/10 párrafo 85 .

El contacto con la familia tiene varias consecuencias prácticas para el sistema. Así, por ejemplo, el Comité de Derechos del Niño destaca que para facilitar visitas de los familiares debe internarse a los niños en centros situados en lugares lo más cercanos posible del lugar de residencia de su familia. Véase OG/10 párrafo 87. 
A ello se agrega un conjunto de otros derechos cuyo listado no parece relevante reproducir debido a que se trata de cuestiones bastante sencillas de comprender y que pueden ser revisados en el párrafo 89 de la OG/10 del Comité de Derechos del Niño. Todas ellas apuntan a la idea que la privación de libertad del joven se cumpla en un entorno de seguridad y que permite el cumplimiento de los fines del sistema.

\subsection{4.- Impugnación de la Legalidad de la Privación de Libertad}

Finalmente, un último aspecto de regulación de la prisión preventiva en donde me parece la legislación internacional refuerza el estatuto de garantías en favor de niños y jóvenes imputados respecto de los adultos, dice relación con los mecanismos que permiten impugnar la legitimidad de la privación de libertad durante el proceso.

La norma base que regula esta garantía se encuentra contemplada en el artículo 37 letra d) de la CDN que establece el derecho de todo niño privado de libertad de “....impugnar la legalidad de su privación de libertad...". Me parece que en esta parte no existe una gran diferencia con normas generales del derecho internacional de los derechos humanos contempladas en el Pacto o la Convención Americana que también permiten impugnar la legalidad de las detenciones. En ese contexto, el matiz de diferencia aparece cuando, junto con lo anterior, el artículo 37 letra d) de la CDN establece que “...y a una pronta decisión respecto de dicha acción”. Es decir, junto con establecer la posibilidad de impugnación de legalidad, se establece una obligación adicional a los Estados partes de resolver dicha impugnación en un espacio temporal acotado, muy breve ("pronta decisión"), cuestión no regulada explícitamente en los instrumentos de carácter general.

Esta particularidad del sistema juvenil es consecuencia directa de las mayores restricciones a la extensión temporal que tiene en este caso el uso de la privación de libertad que respecto de los adultos, según ya tuve oportunidad de revisar precedentemente. Es lógico que si la privación de libertad debe ser por el período más breve, esa privación no debiera extenderse como consecuencia de los mecanismos de impugnación de su legalidad. En ese contexto, es curioso que el Comité de Derechos del Niño que tiene una posición bastante rigurosa en el tema, al momento de ejemplificar los alcances de la idea de lo que es una pronta decisión señale "El derecho a una pronta decisión significa que la decisión debe adoptarse lo antes posible, por ejemplo, en un plazo de dos semanas a partir de la impugnación". ${ }^{63}$ Creo muy desafortunado el ejemplo ya que un plazo de dos semanas para resolver una impugnación de esta naturaleza está muy por debajo del estándar habitual de resolución de estos temas en muchos países en la legislación procesal penal general. Por eso estimo preferible quedarse con el criterio que sea "lo antes posible" expresado por el propio Comité.

63 Véase OG/10 párrafo 84. 
El derecho a un juzgamiento especializado de los jóvenes infractores en el derecho internacional de los derechos humanos y su impacto en el diseño del proceso penal juvenil.

\section{2.- Exigencias más Estrictas Respecto a la Extensión Temporal del Proceso}

La extensión temporal excesiva de los procesos es una preocupación muy importante en el sistema internacional de derechos humanos. Esta preocupación da pie a una garantía básica del debido proceso contemplada en los tratados internacionales de carácter general, por ejemplo en el artículo 14.1 del Pacto, el artículo 8.1 de la Convención Americana y el artículo 6.1 del Convenio Europeo, conocida como el "derecho a ser juzgado en un plazo razonable". Las ideas que fundamentan a esta garantía tienen que ver tanto con el impacto negativo que la extensión temporal del proceso produce en los derechos de las personas imputadas (extendiendo en demasía el estado de incertidumbre generado por el proceso, dificultando la posibilidad de ejercer derecho de defensa, entre otros) como en la legitimidad del sistema frente a la comunidad (la clásica idea expresada en el aforismo inglés "justice delayed, justice denied"). ${ }^{64}$

Debido a que el derecho a ser juzgado en un plazo razonable es una garantía general del debido proceso en la legislación internacional, ella se hace extensible también a los niños y jóvenes imputados sin necesidad que exista una norma específica. No obstante lo anterior, los instrumentos internacionales específicos se hacen cargo de este derecho y al revisar la manera en que lo regulan nuevamente se puede ver que el sistema internacional recoge una idea reforzada de esta garantía en favor de niños y jóvenes. En efecto, allí donde el lenguaje ocupado por la Convención Americana es "el plazo razonable" y en el Pacto "proceso sin dilaciones indebidas" el artículo 40.2 letra b) inciso iii) de la CDN establece el derecho a "Que la causa sea dirimida sin demora". En el mismo sentido, la regla n 20.1 de las Reglas de Beijing establece que "Todos los procesos se tramitarán desde el comienzo de forma expedita y sin demoras innecesarias." El acento de las normas en materia juvenil está dado por la idea del proceso "sin demora". Al interpretar la norma de la CDN el Comité de Derechos del Niño ha establecido de manera expresa que la expresión sin demora es más fuerte que la expresión "sin dilaciones indebidas" del Pacto ${ }^{65}$, la cual normalmente es entendida con idéntico significado a la expresión "plazo razonable" contenida en la Convención Americana. ${ }^{66}$

La consecuencia lógica de esta diferencia en favor de los niños y jóvenes es que la duración total del proceso para ellos debiera ser más breve que tratándose de adultos, aún cuando no hubiera privación de libertad en su desarrollo. Determinar en concreto y con precisión cuando se cumple con esto resulta de extrema dificultad. Como hemos visto en una sección previa, la jurisprudencia internacional ha sido reacia a la idea de determinar en abstracto plazos máximos de duración de un proceso para ser compatibles con la garantía en estudio, prefiriendo un

64 Para análisis general de esta garantía véase Pastor, El plazo, cit. nota n. 54. Trechsel, Human, cit. nota n. 31, pp. 134 a 149.

65 Véase OG/10 párrafo 51.

66 Véase Trechsel, Human, cit. nota n. 31, p. 135. 
conjunto de criterios bastante abiertos para determinar caso a caso cuándo la extensión temporal supera lo razonable o en el caso de los jóvenes constituye una "demora" que puede dar lugar a la violación de este derecho. No obstante lo anterior, el Comité de Derechos del Niño recomienda a los Estados partes, como forma de garantizar este derecho reforzado, fijar y respetar plazos máximos de duración de distintas etapas del proceso subrayando la idea que "Estos plazos deben ser más cortos que los establecidos para los adultos". ${ }^{67}$

Antes de pasar al próximo punto creo indispensable detenerme en un aspecto más general sobre la especial celeridad que deben tener los procesos en materia juvenil. Una revisión de las opiniones del Comité de Derechos del Niño, como también de los comentarios a las Reglas de Beijing, da cuenta que la idea de celeridad está asociada a dos objetivos distintos que en algún momento pueden entrar en contradicción. ${ }^{68}$ Por una parte, su justificación se explica en la misma lógica de la garantía general del derecho a ser juzgado en un plazo razonable que ya he mencionado brevemente. Pero por otra parte, la celeridad se asocia a una característica indispensable que debe tener el sistema para satisfacer adecuadamente la lógica que impone el principio educativo, es decir, para asegurar que la eventual sanción que se imponga al joven cumpla con su efecto pedagógico. ${ }^{69}$ La celeridad asociada el principio educativo tiene diversas consecuencias en el diseño de un proceso cuyo análisis dejo pendiente para un capítulo posterior. En esta sección me ha interesado remarcar la diferencia con el proceso de adultos sólo desde la perspectiva de la dimensión garantística de la idea de mayor celeridad.

\section{3.- Mayores Resguardos al Derecho de Defensa}

Otra de las garantías bases del debido proceso general está constituida por el derecho de defensa. ${ }^{70}$ Se trata de un derecho con amplio reconocimiento en todos los tratados internacionales generales. Por lo mismo, como ya hemos visto en forma precedente, tiene una amplia aplicación también en los procesos en contra de niños y jóvenes.

Antes de entrar al análisis detallado de las diferencias establecidas en favor de los jóvenes, me parece de interés destacar un par de cuestiones generales acerca de la regulación de este derecho en los tratados internacionales de derechos humanos que es necesario tener presente como marco general. En primer lugar, a diferencia de buena parte de las otras garantías

\footnotetext{
$67 \quad$ OG/10 párrafo 52.

68 Véase especialmente OG/10 párrafo 51 y Comentario a la regla no 20.1 de las Reglas de Beijing.

69 Por ejemplo el Comité de Derechos del Niño señala en el párrafo 51 de su OG/10 que "Cuanto más tiempo pase, tanto más probable será que la respuesta pierda su efecto positivo y pedagógico y que el niño resulte estigmatizado". Por su parte el Comentario de la regla n 21.1 enfatiza que la rapidez del proceso es indispensable para evitar el riesgo que los efectos positivos del proceso y la resolución se pierdan.

70 En general sobre el derecho de defensa como garantía básica del proceso penal véase Maier, Julio, Derecho procesal Penal Tomo I, Editores del Puerto, Buenos Aires, 1996, pp. 539 a 595.
} 
El derecho a un juzgamiento especializado de los jóvenes infractores en el derecho internacional de los derechos humanos y su impacto en el diseño del proceso penal juvenil.

específicas que integran al debido proceso, el derecho de defensa presenta diversas caras o dimensiones. Por una parte, claramente tiene el carácter de derecho fundamental de las personas que son objeto de persecución penal, lo que podría ser considerado su cara o dimensión más obvia. Pero además de ello, la doctrina procesal ha entendido que el derecho de defensa cumple la función de ser una garantía o un mecanismo para hacer efectiva al resto de las garantías. ${ }^{71}$ Particularmente se ha entendido que la defensa letrada, uno de los componentes del derecho de defensa, constituye uno de los mecanismos que de mejor manera aseguran la posibilidad del imputado de velar por el cumplimiento de otros derechos como la presunción de inocencia, el derecho a un juicio, etc. En ambas dimensiones se trata de un derecho asociado a la idea de reconocer y resguardar derechos fundamentales. Adicionalmente, algunos autores sostienen que en sus orígenes históricos el desarrollo del derecho de defensa, al menos en el mundo europeo, estuvo más asociado a la creación de un sistema de justicia criminal que pudiera ser percibido como legítimo y justo por la comunidad más que a mejorar la posición concreta del imputado o incrementar su autonomía. Es decir, con una lógica legitimadora del sistema más allá de su función de garantía individual. ${ }^{72}$ De esta forma, se puede observar que el derecho de defensa presenta tensiones que emanan de esta diversidad de dimensiones, por ejemplo el derecho a defenderse personalmente versus la defensa por abogado que se impone obligatoriamente en diversos sistemas procesales penales, al menos para algunas etapas del procedimiento.

Una segunda cuestión que me interesa mencionar es que el derecho de defensa es uno de los componentes del debido proceso de mayor complejidad en relación a los elementos que lo integran de acuerdo a las normas que lo regulan en el derecho internacional de los derechos humanos. En efecto, la mayoría de las garantías se manifiestan en una cláusula específica de los tratados internacionales, como por ejemplo el derecho a ser juzgado en un plazo razonable, la imparcialidad del tribunal, entre otros. Sin embargo, cuando se estudia la forma en que el derecho de defensa se encuentra consagrado en la legislación internacional, se puede apreciar que las distintas dimensiones que lo integran se encuentran contenidas en múltiples normas que dan cuenta de diversas manifestaciones. Sin hacer un listado completo se pueden mencionar: la comunicación previa y detallada de los cargos en contra del imputado (regulada en los artículos 14.3 del Pacto y 8.2 b) de la Convención Americana); derecho a ser asistido por un intérprete (regulado en los artículos 14.3 f) del Pacto y 8.2 a) de la Convención Americana); el derecho a disponer de los tiempos y medios adecuados para el ejercicio de la defensa (regulado en los artículos 14.3 b) del Pacto y 8.2 c) de la Convención Americana); el derecho a presentar

71 Véase Binder, Alberto, Introducción al Derecho Procesal Penal, Editorial Ad-Hoc, Buenos Aires, 1993, p. 151; Riego, Cristián, "El Proceso Penal Chileno y los Derechos Humanos: Volumen I Aspectos Jurídicos", Cuaderno de Análisis Jurídico serie de publicaciones especiales $n^{\circ} 4$, Facultad de Derecho Universidad Diego Portales, Santiago, 1994, p. 52..

72 Véase Summers, Sarah, Fair Trials: The European Criminal Procedural Tradition and the European Court of Human Rights, Hart Publishing, Oxford, 2007, pp. 61 y siguientes. 
prueba u obtener comparencia de testigos (regulado en los artículos 14.3 e) del Pacto y 8.f ) de la Convención Americana); el derecho a interrogar testigos (regulado en los artículos 14.3 e) del Pacto y 8.2 f) de la Convención Americana); derecho a hallarse presente en el proceso (regulado en el artículo 14.3 d) del Pacto); el derecho a defenderse personalmente (regulado en los artículos 14.3 d) del Pacto y 8.2 d ) de la Convención Americana); derecho a ser asistido por un defensor de confianza o elección (regulado en los artículos $14.3 \mathrm{~d}$ ) del Pacto y $8.2 \mathrm{~d}$ ) de la Convención Americana); derecho a contar con un defensor gratuito proporcionado por el Estado (regulado en los artículos 14.3 d) del Pacto y 8.2 e) de la Convención Americana);y, derecho a comunicarse libre y privadamente con el defensor (regulado en los artículos $14.3 \mathrm{~d}$ ) del Pacto y 8.2 d ) de la Convención Americana). ${ }^{73}$

Se puede apreciar que se trata de una regulación bastante importante. Ella contrasta con la contenida en la CDN que se refiere de manera expresa sólo a dos disposiciones en el artículo 40.2 b) ii y vi. Con todo, como veremos a continuación, estas normas establecen algunas diferencias significativas en favor de los jóvenes. Obviamente en todo lo no regulado explícitamente por la CDN se hace aplicable la legislación internacional general.

\subsection{1.- Derecho a la Información Directa y sin Demora de los Cargos:}

Un elemento base sobre el cual se construye el derecho de defensa es el conocimiento oportuno de los cargos que se imputan a la persona objeto de persecución penal de manera tal que, a partir de ese conocimiento, pueda desarrollar actividades conducentes a la construcción de su defensa. Sin información de cargos no hay posibilidad de desarrollar una estrategia de defensa efectiva. Es por esta razones que dicha garantía se recoge en los todos los tratados internacionales generales, como por ejemplo en los en los artículos 14.3 del Pacto, y 8.2 b) de la Convención Americana y 6.3 a) del Convenio Europeo.

Este componente también encuentra regulación en la CDN en su artículo 40.2 b) ii, el que pone un matiz de diferencia respecto a la redacción general. Así, el Pacto regula este derecho señalando que toda persona tiene derecho "A ser informada sin demora, en un idioma que comprenda y en forma detallada, de la naturaleza y causas de la acusación formulada contra de ella". La Convención Americana por su parte lo regula en forma más escueta como el derecho a una "Comunicación previa y detallada al inculpado de la acusación formulada". Frente a esto la CDN regula el derecho a "Que sea informado sin demora y directamente o, cuando sea procedente, por intermedio de sus padres o representantes legales, de los cargos que pesan contra de él..." (el subrayado es mío).

73 Un análisis de varias de estas dimensiones puede verse en Riego, Cristián, "El Sistema Procesal Penal Chileno frente a las Normas Internacionales de Derechos Humanos", en Sistema Jurídico y Derechos Humanos, Cuadernos de Análisis Jurídico serie especial n ${ }^{\circ}$ 6, Facultad de Derecho Universidad Diego Portales, Santiago, 1996, pp. 241 y siguientes. 
El derecho a un juzgamiento especializado de los jóvenes infractores en el derecho internacional de los derechos humanos y su impacto en el diseño del proceso penal juvenil.

Una primera cuestión acerca de la información en donde hay similitudes con el Pacto es el aspecto temporal (la Convención Americana en cambio no regula el aspecto temporal según se puede observar de la cláusula transcrita). De acuerdo a ambos textos la información debe ser realizada sin demora. El Comité de Derechos Humanos del Pacto ha entendido esto como tan pronto el cargo ha sido formulado por la autoridad competente, lo que debiera ocurrir a su vez cuando la autoridad competente decida tomar pasos en contra de la persona sospechosa o dé a conocer públicamente su nombre. ${ }^{74}$ Por su parte, el Comité de Derechos del Niño en su OG/10 sostiene que sin demora y directamente significa "...lo antes posible, es decir, cuando el fiscal o el juez inicien las actuaciones judiciales en contra del niño". ${ }^{75}$ Se trata de interpretaciones bastante similares. Con todo, un matiz de diferencia aparece en la opinión del Comité de Derechos del Niño, el cual se hace cargo de una situación que debiera presentarse con mayor frecuencia en los jóvenes imputados como es lo que ocurre en las hipótesis de remisión de los casos previa a la intervención judicial. En esas hipótesis el Comité de Derechos del Niño sostiene que "Sin embargo, cuando las autoridades deciden ocuparse sin recurrir a procedimientos judiciales, el niño también debe ser informado de los cargos que pueden justificar este criterio". ${ }^{76}$ Como se verá en el capítulo 5 de este trabajo, se trata de una regulación consistente con lo que analizaré a propósito de los sistemas de remisión de casos destinada a resguardar los derechos del niño en esas hipótesis y que no se presenta como una exigencia tratándose de los sistemas de adultos.

Junto con el aspecto temporal, existe una preocupación de la legislación internacional especial en asegurar que la comunicación de los cargos se haga de una manera que sea comprensible, lo que obviamente supone considerar en forma especial el nivel de desarrollo y madurez del imputado. Ello no solamente supone la presencia de traductores en el evento de estar en presencia de un extranjero, cuestión que aparece recogida en los tratados internacionales generales, sino como dice el Comité de Derechos del Niño debe implicar ' “...una 'traducción' de la jerga jurídica oficial que a menudo se utiliza en las imputaciones penales contra menores" 77

De manera de reforzar lo anterior, el Comité de Derechos del Niño sugiere dos medidas adicionales que marcan una diferencia con el tratamiento de adultos. La primera es que para cumplir con el deber de información no basta con entregarle al niño una copia de la acusación escrita sino que en muchas ocasiones se requerirá una explicación oral directa de las autoridades de persecución penal (policía, fiscales o jueces), siendo responsables ellas de la adecuada comprensión del niño. Además, se sugiere entregar la misma información a los padres o representantes legales del niño con el objeto que éste pueda tener una mejor comprensión de

\footnotetext{
74 Comité de Derechos Humanos, Comentario General nº 13, 1984, párrafo 8.

75 OG/10 párrafo 47.

Idem.

Ibid.
} 
los cargos y sus consecuencias. ${ }^{78}$ En esta misma dirección las Reglas $\mathrm{n}^{\mathrm{0}} 7$ y 10.1 de las Reglas de Beijing establecen la necesidad de información a los padres o tutores de los procesos seguidos en contra de los jóvenes o niños imputados. Sobre este punto la Corte Interamericana ha tenido oportunidad de pronunciarse en un caso referido a la situación de jóvenes detenidos señalando que “...el derecho de los detenidos a establecer comunicación con terceros, que les brindan o brindarán asistencia y defensa, se corresponde con la obligación de los agentes estatales de comunicar inmediatamente la detención del menor a esas personas, aún cuando éste no lo haya solicitado". ${ }^{79}$ Se puede observar que el deber de información tiene una extensión a un grupo adicional que normalmente no debe ser considerado tratándose de la persecución penal de un adulto. Además de ello pone exigencias más altas a las autoridades del sistema tanto en el tipo y formato en el que se entrega la información, como en quien tiene la responsabilidad de la adecuada comprensión de la misma.

\subsection{2.- Derecho a Ser Escuchado en Forma Directa:}

Como ya se señaló, el derecho de defensa incluye la posibilidad de defenderse personalmente, no obstante lo común será que sea ejercido en la práctica por medio de un asistente profesional (abogado). En esta dirección, probablemente vinculado con otros derechos generales de los niños como el derecho de participación, la CDN contempla exigencias fuertes respecto a la participación de los niños en el proceso, especialmente enfatizando la posibilidad que intervengan en forma directa dando su opinión respecto a las decisiones que lo puedan afectar. Esta dimensión del derecho a defensa no aparece regulada con la misma fuerza en la legislación internacional general.

El artículo 12 de la CDN contiene la norma genérica al respecto. En su número uno establece el derecho general a expresar su opinión en todos los asuntos que lo afectan. El numeral dos, establece específicamente el derecho que tiene de ser escuchado en todo procedimiento judicial o administrativo ya sea directamente o por medio de su representante. Frente a esta norma el Comité de Derechos del Niño -en su OG/10- ha enfatizado que el niño tiene derecho a ser escuchado directamente y no sólo por medio de su representante si es en el interés superior del niño, derecho que - además- debe ser respetado en todas las etapas del proceso incluida la de ejecución de las medidas impuestas (por ejemplo permitiéndole exponer su opinión acerca de las medidas que podrían imponérsele). Para su adecuado ejercicio se indica que este derecho supone información previa no sólo de los cargos en su contra sino que

\footnotetext{
78 Véase OG/10 párrafo 48.

79 Sentencia de la Corte Interamericana de Derechos Humanos de 18 de septiembre de 2003 caso Bulacio Contra Argentina párrafo 136. Un análisis más completo de dicho fallo puede revisarse en Berríos, Gonzalo, "Derechos de los Adolescentes y Actividad Persecutoria Previa al Control Judicial de la Detención”, en Justicia y Derechos del Niño $n^{o}$ 8, Santiago, 2006,, pp. 159 a 196, ver especialmente pp. 167 a 170.
} 
El derecho a un juzgamiento especializado de los jóvenes infractores en el derecho internacional de los derechos humanos y su impacto en el diseño del proceso penal juvenil.

también del propio proceso y de las medidas que pueden adoptarse como consecuencia del mismo. ${ }^{80}$

Sin perjuicio de lo anterior, la legislación internacional reconoce que muchas veces no basta la posibilidad que tiene el joven de ser escuchado, sino que requerirá asistencia adecuada para poder manifestar sus puntos de vista. Sobre este derecho trata la sección siguiente.

\subsection{3.- Derecho a la Asistencia Apropiada}

Ya mencionaba que la participación directa del joven puede no ser suficiente para asegurar que sus puntos de vista sean presentados satisfactoriamente ante las autoridades como sus intereses defendidos de manera eficaz en sede judicial. Para garantizar que esto ocurra, la legislación internacional especial contempla el derecho a una asistencia apropiada (artículos 37 d) y 40.2 b) ii y iii de la $\mathrm{CDN}^{81}$, regla ${ }^{\circ} 15.1$ Reglas de Beijing). Si bien el derecho a contar con asistencia apropiada es similar al derecho a la asistencia jurídica regulado en la legislación internacional general, existen algunas dimensiones que lo diferencian sobre las cuales me detendré brevemente.

Una primera diferencia que puede apreciarse con la garantía general de los tratados internacionales es que en ella el foco de las reglas está en el otorgamiento de asistencia letrada o jurídica (prestada por abogados) en favor de los imputados. La legislación especial internacional, en especial la CDN, permite en cambio que esa asistencia sea prestada por otros profesionales (por ejemplo asistentes sociales) en la medida que sea "apropiada". Si bien esto podría ser leído en desmedro de los niños y jóvenes imputados, en mi opinión lo que hacen estas normas es ampliar al ámbito de protección del derecho internacional al establecer como obligatoria la asistencia al niño en todo caso allí en donde tratándose de los adultos no exige una obligación para todo tipo de casos, incluso los penales, y menos que ésta sea gratuita a todo evento. ${ }^{82}$ En este contexto, la exigencia de asistencia apropiada asegura la presencia de un asesor idóneo a todo evento.

Sin perjuicio de lo anterior y reconociendo la discrecionalidad que disponen los Estados partes en la materia, el Comité de Derechos del Niño recomienda que en la mayor medida posible la asistencia sea otorgada por profesionales del área jurídica, ya sea abogados

\footnotetext{
$80 \quad$ Véase OG/10 párrafos 44 y 45.

81 Art. 37 d) “...derecho a un pronto acceso a la asistencia jurídica y otra asistencia adecuada...”, Art. 40.2 b) ii “...y que dispondrá de asistencia jurídica u otra asistencia apropiada en la preparación y presentación de su defensa"; art. 40.2 b) iii “...en presencia de un asesor jurídico u otro tipo de asesor adecuado..."

82 Para un análisis general de la legislación internacional y su jurisprudencia en este punto recomiendo Trechsel, Human, cit. nota n. 31 pp. 270 y siguientes.
} 
especializados o personal parajurídico. En caso de no tener especialidad jurídica, se recomienda que los profesionales tengan conocimiento y comprensión suficiente de los aspectos jurídicos de la justicia de menores, como también formación para trabajar con niños en conflicto con la justicia. $^{83}$

Además del asesor apropiado, las normas internacionales ponen especial énfasis en tres elementos que deben acompañar al asesoramiento para que éste pueda ser efectivo. ${ }^{84}$ En primer lugar, debe tratarse de un asesoramiento oportuno (art. $37 \mathrm{~d}$ ) CDN regula esto específicamente a propósito de los niños privados de libertad estableciendo la necesidad de asegurar pronto acceso a la asistencia). La idea de oportunidad está asociada a que la intervención del asesor debiera producirse en forma temprana en el proceso y no necesariamente desde que éste se haya judicializado. ${ }^{85}$ En segundo término, la asesoría debe ser gratuita sin distinción ${ }^{86}$, lo que constituye una diferencia con los tratados internacionales generales como el Pacto o el Convenio Europeo que califican esa posibilidad a la existencia de un interés especial (de la justicia) y la falta de medios del imputado (véase por ejemplo el artículo 14.3 d) del Pacto). Finalmente, debe tratarse de una asesoría permanente y que se extienda durante todo el proceso. ${ }^{87}$

La asistencia apropiada no se agota con la participación del defensor u otro profesional, sino que la legislación internacional especial regula con bastante detalle la intervención de los padres o tutores. ${ }^{88}$ Se trata obviamente de una regulación exclusiva para los niños que no encuentra correlato en la legislación de adultos. Así, la regla 15.2 de las Reglas de Beijing de manera expresa regula el derecho de ellos a participar en las actuaciones del procedimiento, admitiendo la posibilidad que tiene la autoridad de denegar su participación si ella fuera más conveniente para la defensa de los derechos del niño. Por ejemplo, en casos de padres que presionaran a sus hijos para "reconocer sus errores" ante la autoridad o que por su sola presencia

83 Véase OG/10 párrafo 50.

$84 \quad$ Un ejemplo de estas tres exigencias en el ámbito del sistema interamericano puede verse en el Informe $n^{\circ} 41 / 49$ Caso no 11.491 de la Comisión Interamericana de Derechos Humanos (Caso Menores Detenidos v. Honduras) de 10 de marzo de 1999 en donde la Comisión señala en su párrafo 152 “...el Estado Hondureño tiene el deber jurídico de proveer de un defensor de oficio a los menores, cuando no tengan defensor particular, en todos los actos procesales y desde el momento en que se les imputa una infracción".

85 En este sentido el Comité de Derechos del Niño señala en el párrafo 52 de la OG/10 que la asistencia no debe limitarse al juicio ante un órgano jurisdiccional sino que se aplica a todas las fases del proceso “.... partir del interrogatorio del niño por la policía.”. Un análisis de la importancia de un acceso temprano al defensor como elemento central para asegurar el derecho de defensa de los jóvenes detenidos puede verse en Berríos, "Derechos" cit. nota n. 81

86 Véase regla $\mathrm{n}^{\circ} 15.1$ de las Reglas de Beijing y OG/10 párrafo 49.

Idem.

88 Se entiende que su presencia en las actuaciones del proceso en contra de un niño pueden producir efectos positivos como el de prestar asistencia psicológica y emotiva al niño. Véase OG/10 párrafo 53. A ello podría que su participación debiera ser un elemento relevante en ayudar al niño a comprender lo que ocurre en el proceso en su contra, sus posibles consecuencias y los derechos que están en juego. 
El derecho a un juzgamiento especializado de los jóvenes infractores en el derecho internacional de los derechos humanos y su impacto en el diseño del proceso penal juvenil.

inhibieran al niño a dar a conocer su punto de vista. Para promover una participación amplia de los padres, el Comité de Derechos del Niño recomienda que a ellos se les notifique lo antes posible acerca de la detención del niño. ${ }^{89}$

Me parece relevante además mencionar un punto adicional que delimita los alcances del derecho a la asesoría del joven como de su derecho a participar en el proceso y que ha sido objeto de jurisprudencia en el sistema europeo de protección de los derechos humanos. La Corte Europea ha señalado que, sin perjuicio de la asistencia de un defensor, la participación real del joven en el proceso presupone su capacidad de comprender "...globalmente la naturaleza y lo que se juega en juicio, concretamente el alcance de toda pena que se puede imponer. Ello significa que el interesado... debe estar en condiciones de comprender a grandes rasgos lo que se diga en el tribunal. Debe ser capaz de seguir las palabras de los testigos de cargo y, si está representado, de exponer a sus abogados su versión de los hechos, señalarles cualquier declaración con la que no esté de acuerdo e informales de cualquier hecho que merezca ser presentado para su defensa" ${ }^{90}$ Con ello se ha enfatizado que el ejercicio de la defensa presupone también la posibilidad de tener una participación real del joven imputado en el proceso.

\section{4.- Exigencias más Estrictas para la Renuncia de Derechos que Integran al Debido Proceso}

Las garantías que forman parte del debido proceso pueden ser objeto de renuncia legítima de parte de su titular. El caso más paradigmático y polémico de esta situación se encuentra en la posibilidad reconocida muy ampliamente en los ordenamientos procesales de adultos de prescindir del derecho básico a que el caso sea resuelto en una audiencia pública, contradictoria y oral. Esto se hace a través de diversos mecanismos de negociación y procedimientos especiales, como lo es el caso del procedimiento abreviado recogido en la mayoría de las legislaciones procesal penales latinoamericanas actuales, aún cuando es objeto de diversas polémicas y debates. ${ }^{91}$

En las legislaciones procesales de adultos se entiende que una renuncia a una garantía del debido proceso es legítima en la medida en que ella sea voluntaria e informada, por lo que buena parte de los resguardos que se adoptan para evitar los potenciales abusos que se podrían generar de parte del aparato de persecución penal están orientados a los mecanismos de

\footnotetext{
89 Véase OG/10 párrafo 54.

90 Sentencia de la Corte Europea de Derechos Humanos de 15 de junio de 2004 caso S.C contra Reino Unido, párrafo 29. La Corte estimó que al tratarse de un joven de 11 años con una edad mental menor no estaba en condiciones de participar realmente en el proceso lo que constituía una violación al art. 6.1 del Convenio Europeo. 91 Una visión panorámica y comparada sobre este punto véase en Maier, Julio y Bovino, Alberto (compiladores), El Procedimiento Abreviado, Editores del Puerto, Buenos Aires, 2001.
} 
verificación de la voluntariedad y a sistemas especiales de revisión de la comprensión que tiene el titular del derecho que renuncia de las consecuencias de la misma.

Tratándose de los niños y jóvenes que son objeto de persecución penal me parece claro que también debe existir el reconocimiento a la posibilidad que tienen de renunciar a ciertos derechos procesales, especialmente cuando esa renuncia les puede permitir obtener una mejor posición para satisfacer sus intereses. El no reconocer esta posibilidad significa volver a la lógica de incapacidad del "menor" que inspiró a los sistemas tutelares previos al modelo de responsabilidad impuesto por la CDN. Por otra parte, hay que estar atentos a los riesgos que se abren frente a renuncias que solo son formalmente voluntarias e informadas, como por ejemplo cuando el niño no comprende con claridad el significado y consecuencias jurídicas de la renuncia o cuando la decide producto de presiones psicológicas de parte de las autoridades de persecución penal que un adulto normalmente está en condiciones de resistir.

En este contexto, me parece que el gran desafío que impone la legislación internacional a los Estados es el de reforzar los mecanismos de aseguramiento de la voluntariedad e información que deben tener los jóvenes al momento de renunciar a un derecho tomando especialmente en consideración que por su madurez y estado de desarrollo personal no tienen las mismas capacidades que un adulto. Nuevamente estamos en presencia de una exigencia adicional o reforzada del debido proceso respecto a los adultos que emana precisamente de la situación diferente en que se encuentran los niños para enfrentar un proceso.

El análisis concreto de las condiciones para renunciar a un derecho específico me parece pueden ilustrar el cómo la legislación internacional especial se hace cargo de esta necesidad de mayor protección. Estimo que un caso paradigmático está constituido por el derecho a no autoincriminarse. Este derecho está regulado en el artículo 40.2 b) iv de la CDN que señala que todo niño imputados tiene derecho a no ser "... obligado a prestar testimonio o declararse culpable..". ${ }^{92}$

Las diferencias de alcance de esta garantía respecto a los adultos no queda establecida con el puro análisis de los textos legales como ha ocurrido frente a otros elementos del debido proceso analizados en forma precedente. Por el contrario, tanto el Pacto -en su artículo $14.3 \mathrm{~g}$ )como la Convención Americana -en su artículo 8.2 g)- regulan este derecho de una manera muy similar a la CDN señalando que el imputado tiene derecho “.... a no ser obligado a declarar

Un análisis comparativo de la renuncia al derecho a guardar silencio en Chile y los Estados Unidos puede verse en Estrada, Francisco, "La Renuncia del Derecho a Guardar a Silencio por un Adolescente en Nuestro ordenamiento Jurídico y en el Estadounidense. Comentario a propósito del fallo In Re E.T.C Juvenile 141 Vt. 375 (1982) Corte Suprema de Vermont 24 de junio de 1982", en Revista de Derechos del Niño no 3/4, Santiago 2006, pp. 181 a 196. 
El derecho a un juzgamiento especializado de los jóvenes infractores en el derecho internacional de los derechos humanos y su impacto en el diseño del proceso penal juvenil.

contra sí mismo ni a declararse culpable." (el Pacto utiliza la palabra "confesarse" en vez de la palabra "declararse"). Las diferencias están, consecuentemente, en los alcances de esta regla tratándose de niños o jóvenes. En esta dirección el Comité de Derechos del Niño ha señalado en su OG/10 varias cuestiones de interés. La primera de ellas es reconocer que la idea de ser "obligado" debe entenderse de manera amplia no sólo incluyendo las situaciones de violencia física (tratos crueles, inhumanos o degradantes) sino que también de carácter psicológico. ${ }^{93} \mathrm{El}$ Comité recalca que para determinar los casos de violación de este derecho fuera de las hipótesis más obvias debe considerarse especialmente "la edad o el grado de desarrollo del niño, la duración del interrogatorio, la falta de comprensión por parte del niño, el temor a las consecuencias desconocidas...." ${ }^{94}$ En consecuencia, es necesario incluir aspectos muy particulares que sólo están presentes tratándose de niños y jóvenes para evaluar la violación al derecho a no autoincriminarse. Eso debiera traducirse en situaciones en las cuáles una declaración prestada en condiciones equivalentes por un niño y por un adulto podría tener resultados diversos respecto a su legitimidad.

De manera de reforzar lo anterior, el Comité de Derechos del Niño establece como obligación para los Estados partes de permitir que a los interrogatorios a los que se somete al niño deben tener acceso los representantes legales u otros apropiados e incluso la posibilidad que se solicite la presencia de los padres. ${ }^{95}$ Esta exigencia es un poco más estricta que tratándose de adultos, en donde no necesariamente se requiere la presencia de un defensor para darle legitimidad a la declaración policial. Finalmente, el Comité recomienda que policías y otros agentes encargados de tomar las declaraciones de los niños sean entrenados especialmente para evitar la obtención de confesiones de baja credibilidad o producto de coacción. ${ }^{96}$

\section{4.- Segundo Eje: Estructura General del Procedimiento}

Un segundo eje de análisis en donde me parece el principio de especialidad tiene un impacto relevante en el área procesal está vinculado a un conjunto misceláneo de elementos de diseño de un proceso que un sistema jurídico debiera contemplar para satisfacer objetivos

La presión psicológica o de otro tipo para obtener declaraciones autoinculpatorios también ha sido reconocida como contraria al derecho a no autoincriminarse tratándose de adultos en el derecho internacional y la legislación comparada desde hace décadas. Una visión panorámica sobre las declaraciones policiales en los Estados Unidos que puede ser útil para ver este punto puede revisarse en Baytelman, Andrés. 2002. "Tiene Derecho a Guardar Silencio..." la Jurisprudencia Norteamericana sobre Declaración Policial, Informe de Investigación $n^{\circ}$ 13, Centro de Investigaciones Jurídicas de la Facultad de Derecho Universidad Diego Portales, Santiago, 2002. OG/10 párrafo 57. Esto es complementado también en el párrafo 58. Idem párrafo 58. Este es uno de los temas que surge con mayor fuerza en la jurisprudencia del caso de la Corte Suprema de Vermont, analizado por Francisco Estrada. Como se refiere a un tema de derecho comparado lo dejo reservado para el trabajo futuro que realizaré sobre la materia. En todo caso véase Estrada, "La renuncia", cit. nota n. 94, pp.185 y 186.

96 Ibid. 
específicos o propios de la justicia juvenil, como lo son por ejemplo el principio educativo o el resguardo de la privacidad de los niños. Se trata de valores que imponen consecuencias procesales que, en muchos casos, se oponen o entran en competencia o contradicción (al menos aparente) con valores del debido proceso y por eso requieren un análisis separado de este mismo. Esto no quiere decir, en todo caso, que algunos de los elementos o mecanismos procesales a través del cual se manifiestan estos valores pueden también cumplir con funciones de resguardo del debido proceso. Esta circunstancia lleva en muchos casos a que en el ámbito internacional y en el derecho comparado se presenten o estudien a propósito del tema y, por lo mismo, no se distingan con claridad.

No creo posible avanzar en una suerte de teoría general de estos otros aspectos del proceso juvenil sin hacer referencia directa a los valores o ideas que se encuentran detrás de ellos. Realizando una selección de las cuestiones más significativas estimo posible identificar tres elementos estructurales de diseño procesal. Estos son: la flexibilidad del proceso; la protección de la privacidad de los jóvenes y el énfasis en el joven. A continuación revisaré cada uno de ellos extrayendo las principales consecuencias procesales que debieran tener en las legislaciones internas.

\section{1.- Necesidad de Tener un Proceso Flexible y Liviano:}

La idea que los procesos seguidos en contra de niños y jóvenes presenten niveles mayores de flexibilidad o sean concebidos como "más livianos" que los de los adultos es una consecuencia del "principio educativo" que impera en los sistemas de justicia juvenil. ${ }^{97}$ Así, por ejemplo, en el caso alemán, Albrecht sostiene que la doctrina de dicho país enfatiza que a partir de ese principio el proceso penal debe ser especialmente elástico y que preceptos rígidos deben mantenerse circunscritos a la medida mínima inevitable pues la hipertrofia de lo formal impide a menudo -ya en el planteamiento- la realización del principio educativo. ${ }^{98}$ De ello precisamente deduce la necesidad de una aceleración especial de este tipo de procedimientos. ${ }^{99}$

97 Los alcances del principio educativo son objeto de amplio desarrollo y debate, tema sobre el cual no puedo ir en este trabajo. Con todo, me parece pacífico que se trata de un principio básico sobre el que se construyen los sistemas de responsabilidad penal juvenil. En este sentido se ha dicho "Se trata, en definitiva, de un principio configurador del derecho penal juvenil, en tanto afecta todos los ámbitos de este sistema -desde el procesal (celeridad, carácter instructor del fiscal de menores, posibilidad de resolución informal del caso, etc.) hasta el relativo a las consecuencias jurídicas (catálogo variado de medidas, criterios flexibles de aplicación y modificación)-; siendo así que su análisis resulta imprescindible de cara a fijar los criterios que participan en la determinación de la intervención operada sobre el menor infractor" Cruz, Beatriz, Educación y Prevención General en el Derecho Penal de Menores, Marcial Pons, Barcelona, 2006, p. 23. Información sobre el debate acerca de los alcances del principio educativo pueden revisarse en el mismo texto pp. 23 a 31. Albrecht, El derecho, cit. nota n. 7. p. 407.

Idem p. 408. 
El derecho a un juzgamiento especializado de los jóvenes infractores en el derecho internacional de los derechos humanos y su impacto en el diseño del proceso penal juvenil.

Se trata de una idea recogida con fuerza también en la normativa internacional. Así, el comentario de la regla $\mathrm{n}^{\mathbf{0}} 20$ de las Reglas de Beijing esclarece bastante este punto cuando señala "La rapidez en la tramitación de los casos de menores es de fundamental importancia. De no ser así peligrarían cualesquiera efectos positivos que el procedimiento y resolución pudieran acarrear. Con el transcurso del tiempo, el menor tendrá dificultades intelectuales y psicológicas cada vez mayores, por no decir insuperables, para establecer una relación entre el procedimiento y la resolución, por una parte, y el delito, por otra."

Se puede apreciar que el énfasis no está en la idea de garantía de "plazo razonable" destinada a evitar el estado de incertidumbre generado por el proceso o el desmedro que su extensión podría tener para la presunción de inocencia que ya tuve oportunidad de revisar. Lo que se persigue, en cambio, es asegurar la finalidad educativa que los propios tratados internacionales exigen a los procesos juveniles. En consecuencia, el punto es que para jóvenes se necesita contar con procedimientos muy expeditos para la protección de valores diversos a los del debido proceso o que incluso podrían producir aparentes colisiones con el mismo (por ejemplo cuando a partir de una excesiva celeridad o flexibilidad del procedimiento no se otorgue un espacio real al niño para el ejercicio del derecho de defensa).

Esta filosofía también puede ser leída de otras disposiciones de la Reglas de Beijing. Así, por ejemplo, cuando la regla $n^{\circ} 6.1$ procura entregar amplia discrecionalidad a las autoridades en distintas etapas del proceso se está pensando, según lo dice el propio comentario de la regla, en la idea que en su desarrollo se puedan ir adoptando medidas adecuadas a cada caso particular, sin que exista una legislación rígida que opere como una camisa de fuerza. ${ }^{100}$ En una menor medida, esto se refleja también en la regla $n^{\circ} 14.2$ de las Reglas de Beijing cuando establece que el proceso debe desarrollarse en “...un ambiente de comprensión...”. ${ }^{101}$

En este escenario, la pregunta relevante en términos de diseño procesal tiene que ver con el tipo de impacto posible de esta lógica o filosofía. Como hemos visto, la legislación internacional suele dejar un margen de apreciación importante a los Estados para decidir como instrumentalizar los principios reconocidos en ella. En esta área en particular no existen directrices u opiniones específicas en el ámbito internacional que indiquen una fórmula concreta

\footnotetext{
100 Véase Comentario a regla ${ }^{\circ} 6$ de las Reglas de Beijing.

101 Cabe tener presente que la potencial tensión de objetivos entre las derivaciones del principio educativo y las garantías del debido proceso que surgen de la lectura de las Reglas de Beijing mencionadas en este párrafo se explican en buena medida debido a que éstas, por el momento histórico que se dictaron, no son un reflejo completo de la lógica impuesta por la CDN que es posterior. En este sentido se ha afirmado que "De ahí que, en muchos aspectos, las reglas de Beijing parezcan estar a mitad de camino entre el modelo tutelar o de la 'situación irregular' y el modelo de la protección integral de los derechos del niño". Véase Beloff, Mary, "Los Equipos Multidisciplinarios en las Normas Internacionales de las que Surge el Modelo de la Protección Integral de Derechos del Niño", en Justicia y Derechos del Niño no 4, Buenos Aires, 2002, p. 38.
} 
de aproximación al tema. Con todo, con el objetivo de poner algunas imágenes del tipo de consecuencia en el diseño procesal que esta idea podría tener -que más adelante me permitirán evaluar el nivel de cumplimiento de las legislaciones nacionales comparadas- me parece posible identificar cuatro estrategias de flexibilización de procedimientos.

En primer lugar, están las estrategias que se podrían denominar como simplificación procesal. Es decir, por vía de las cuales se establecen procesos especiales para los jóvenes que eliminan o reestructuran etapas procesales del proceso de adultos, ya sea en ciertas categorías de hechos (por ejemplo delitos flagrantes) o en atención a la gravedad de los mismos. Un típico caso de simplificación es la eliminación de la etapa de investigación una vez judicializado el proceso o la concentración de etapas procesales en un mismo acto.

Un segundo tipo de estrategias está constituida por el establecimiento de plazos más breves o límites temporales más estrictos para las distintas actividades procesales en el proceso juvenil en relación al de adultos. Se trata de una estrategia que también suele utilizarse como forma de asegurar la garantía de plazo razonable.

Un tercer tipo de estrategias, supone el rediseño de los sistemas de impugnación, particularmente de la sentencia definitiva. En muchos sistemas procesales la complejización y extensión temporal de los procesos se explica no tanto por lo que ocurre en instancia sino luego por la amplitud de recursos que es posible interponer contra una sentencia y lo largo del trámite de los mismos. Desde esa perspectiva, una estrategia posible es derechamente la eliminación de algunas vías de impugnación o el establecimiento de vías diferenciadas dependiendo del actor agraviado. Se trata de una estrategia que podría tener roces con garantías del debido proceso en la medida que por vía de la supresión de vías de impugnación el joven condenado se viera imposibilitado de ejercer el derecho a recurrir contemplado en la legislación internacional (artículos 14.5 del Pacto y 8.2 h) de la Convención Americana).

Finalmente, una cuarta posibilidad está en excluir del proceso juvenil algunos debates que normalmente forman parte de los procesos penales de adultos, como por ejemplo la determinación de la responsabilidad civil del joven derivada del hecho constitutivo del delito juzgado.

\section{2.- Protección de la Privacidad (vida privada)}

Otro mandato central de las normas internacionales en relación a la estructura del proceso es que en éste debe resguardarse al máximo la vida privada de los niños en todas sus etapas. La protección de la privacidad del niño durante el proceso seguido en su contra es un valor del sistema que corre bastante alto y que es propio o específico de los sistemas de responsabilidad juvenil. Por lo mismo, se trata de un principio reconocido en forma explícita por instrumentos internacionales especiales. Así, el artículo 40.2 b) vii de la CDN establece "Que se respetará 
El derecho a un juzgamiento especializado de los jóvenes infractores en el derecho internacional de los derechos humanos y su impacto en el diseño del proceso penal juvenil.

plenamente su vida privada durante todo el proceso", el cual debe ser relacionado con una disposición general como el artículo 16 de la misma CDN que establece la prohibición de injerencias arbitrarias o ilegales en la vida privada del menor. Las Reglas de Beijing, por su parte, se hacen cargo de su regulación en las reglas $\mathrm{n}^{\circ} 8$ y nº 21.

El punto de partida de la legislación internacional especial es diverso a la de la general. En efecto, para esta última (por ejemplo artículo 14.1 del Pacto, 8.1 de la Convención Americana y 6.1 del Convenio Europeo) el principio básico de debido proceso que orienta a los sistemas de justicia criminal debe ser la publicidad del juzgamiento, aspecto que ha tenido amplio reconocimiento en la jurisprudencia internacional. ${ }^{102}$

Las razones que justifican este tratamiento claramente diferenciado han sido expuestas por el Comité de Derechos del Niño en su OG/10. Según el Comité el objetivo es evitar que la publicidad indebida del proceso cause daño al niño. En particular, el Comité manifiesta preocupación por la posible estigmatización que genera la publicidad y el efecto que esto puede tener “...en la capacidad del niño para acceder a la educación, el trabajo o la vivienda o conservar su seguridad". ${ }^{103}$ En la misma dirección, el comentario a la regla $n^{\circ} 8$ de las Reglas de Beijing destaca lo especialmente vulnerables que son los jóvenes a la difamación y la existencia de diversos estudios criminológicos que dan cuenta de los efectos perjudiciales que produce la individualización de los jóvenes con categorías como las de delincuente o criminal. ${ }^{104}$ Como puede observarse, las justificaciones emanan de la especial posición en que se encuentran los niños objeto de persecución penal que hace necesario un nivel mayor de resguardo que un adulto. Esto no significa que la publicidad no pueda afectar en algunos casos a los adultos en términos similares que a un joven, el punto es que como principio general el sistema internacional considera que ese perjuicio es menor que la protección del valor de la publicidad de los procesos. Tratándose de los niños esa lógica parece invertirse en la legislación internacional.

En este marco, la protección de la privacidad del niño presenta tres alcances con

102 A modo de referencia, puede revisarse la sentencia de la Corte Interamericana de Derechos Humanos de 22 de noviembre de 2005, caso Palamara Iribarne v/s Chile en el cual la Corte señala en sus párrafos 167 y 168 sobre el rol de la publicidad: “167. El derecho al proceso público consagrado en el artículo 8.5 de la Convención es un elemento esencial de los sistemas procesales penales acusatorios de un Estado democrático y se garantiza a través de la realización de una etapa oral en la que el acusado pueda tener inmediación con el juez y las pruebas y que facilite el acceso al público; 168. La publicidad del proceso tiene la función de proscribir la administración de justicia secreta, someterla al escrutinio de las partes y del público y se relaciona con la necesidad de la transparencia e imparcialidad de las decisiones que se tomen. Además, es un medio por el cual se fomenta la confianza en los tribunales de justicia" (he eliminado las referencias a otros fallos que realiza la Corte). Para el caso del sistema europeo véase como ejemplo Sentencia de la Corte Europea de Derechos Humanos de 26 de septiembre de 2000 caso Guisset vs. Francia que desarrolla la ida de la publicidad en términos bastante similares. OG/10 párrafo 64.

104 Véase Comentario Regla n ${ }^{\circ} 8$ Reglas de Beijing. 
implicancias de carácter procesal sobre los cuales es necesario detenerse. El primero de ellos tiene que ver con el ámbito que queda cubierto por la cláusula de protección de privacidad. El sistema internacional se orienta a tener una comprensión amplia y no formal de la protección. Es decir, no se trata simplemente de una obligación de no dar a conocer el nombre y apellido de un niño sometido a una persecución penal, sino que como lo señala la regla $\mathrm{n}^{\circ} 8.2$ de las Reglas de Beijing debe abarcar la publicación de cualquier información "...que pueda dar lugar a la identificación de un menor delincuente". En el mismo sentido se ha pronunciado el Comité de Derechos del Niño sobre los alcances de la protección, pero poniendo especial énfasis en el cuidado que debe existir de parte de autoridades en la elaboración y difusión de comunicados públicos en delitos cometidos por niños y del rol de los periodistas y la prensa en la difusión de los mismos. ${ }^{105}$ Por esta vía los alcances de la protección se hacen extensivos no sólo a las autoridades públicas.

Una segunda cuestión relevante tiene que ver con las limitaciones que impone la protección de privacidad a la publicidad del juicio seguido en contra de los niños. Sobre este punto el Comité de Derechos del Niño sostiene una posición bastante fuerte según la cual en principio los juicios en contra de un niño deben realizarse a puertas cerradas. Según el Comité "El juicio público en la justicia de menores sólo debe ser posible en casos muy precisos y previa autorización por escrito del tribunal. Esta decisión podrá ser apelada por el niño". ${ }^{106}$ Se puede observar que la postura inicial del Comité es la no publicidad del juicio. Incluso se recomienda a los Estados partes establecer reglas en esa dirección, regulando excepciones claras y delimitadas en la ley. Con todo, el Comité estima que el veredicto o la sentencia deberán dictarse en audiencias públicas, pero sin revelar la identidad del niño. ${ }^{107}$ Además, tampoco queda excluida del todo la posibilidad que el juicio sea público.

Las recomendaciones del Comité recaen sobre un tema polémico y muy sensible en la legislación internacional general. En efecto, la publicidad del juicio se ha establecido como un derecho fuerte en los tratados internacionales generales ${ }^{108}$ y ha sido una de las plataformas de cambio con mayor valor simbólico en los procesos de reforma a la justicia penal en América Latina. En este contexto, parece necesario ver cómo se decanta en la jurisprudencia futura del sistema internacional esta recomendación de forma de ver como se compatibilizan intereses que aparecen en claro conflicto.

Un tercer aspecto cubierto por las normas de protección de la privacidad tiene que ver con

OG/10 párrafo 64.

OG/10 párrafo 65.

Idem párrafo 66.

Además de la revisión de la literatura general ya citada puede verse sobre este punto Amnistía Internacional, Juicios Justos, Madrid, 1998, pp. 91 a 94. 
El derecho a un juzgamiento especializado de los jóvenes infractores en el derecho internacional de los derechos humanos y su impacto en el diseño del proceso penal juvenil.

el uso de antecedentes o registros como consecuencia de la persecución en contra de un niño. Se trata de una materia regulada en forma explícita por la regla $\mathrm{n}^{\circ} 21$ de las Reglas de Beijing. La regla $n^{0} 21.1$ señala que "Los registros de los menores delincuentes serán de carácter estrictamente confidencial y no podrán ser consultados por terceros. Sólo tendrán acceso a dichos archivos las personas que participen directamente en la tramitación de un caso en curso, así como otras personas debidamente autorizadas". Por su parte, la regla $\mathrm{n}^{\circ} 21.2$ señala que "Los registros de los menores delincuentes no se utilizarán en procesos de adultos relativos a casos subsiguientes en los que esté implicado el mismo delincuente”.

Se trata de dos cuestiones distintas que hay que analizar separadamente. Respecto a quienes tienen acceso a los registros, la idea base del sistema internacional es que éste sea limitado sólo al mínimo necesario que en principio está constituido sólo por las personas que participan en el caso. Con todo, la regla $\mathrm{n}^{\circ} 21.1$ amplía esto al incluirse a otras personas "debidamente autorizadas". Con todo, el comentario a dicha regla explica que estos otros suelen ser investigadores, es decir, personas que solicitan acceso con fines académicos o de estudio. Entendida de esta forma, la regla parece resguardar con fuerza la vida privada del niño.

La segunda cuestión se refiere al uso futuro que se puede hacer de los registros o antecedentes de los jóvenes infractores. La idea del sistema internacional derechamente es la de impedir que un registro o antecedente juvenil pueda ser invocado en un caso contra la misma persona en el sistema de adultos. Debe notarse que se trata de una situación restringida a un caso bastante puntual y no una prohibición absoluta de uso de antecedentes juveniles, por ejemplo para ser utilizados para decisiones del mismo sistema juvenil (vgr. una medida cautelar personal). El Comité de Derechos del Niño, con el objeto de hacer operativa esta regla, recomienda a los Estados partes a adoptar normas que generen la supresión automática de los registros de antecedentes de los niños al momento de cumplir 18 años o al menos (en casos de delitos graves) que esa supresión se produzca a petición del niño interesado si éste ha cumplido con ciertos requisitos (por ejemplo no haber cometido delitos luego de dos años de la última condena). ${ }^{109}$

\section{3.- Énfasis en el Joven}

Al revisar la legislación internacional, se puede notar claramente que el sistema para jóvenes infractores opera sobre la lógica que las decisiones que se adopten por parte de las autoridades, particularmente al momento de establecer consecuencia para la conducta que se imputa, se hagan considerando de manera especial las características y necesidades concretas del joven infractor.

\footnotetext{
109 Idem párrafo 67.
} 
En esta misma dirección, el Comité de Derechos del Niño señala que las respuestas a los delitos deben ser proporcionadas no sólo a su gravedad y circunstancias sino que también a las necesidades del niño, destacándose que "La aplicación de un método estrictamente punitivo no está en armonía con los principios básicos de la justicia de menores....". ${ }^{110}$ El Comité agrega, frente a consideraciones vinculadas a la gravedad del hecho y las necesidades de orden público para la determinación de sanciones, que "En el caso de los menores siempre prevalecerá sobre estas consideraciones la necesidad de salvaguardar el bienestar y el interés superior del niño y de fomentar su reintegración social". ${ }^{111}$

Las reglas contenidas en distintos instrumentos internacionales son claras a este respecto. Así, por ejemplo, el artículo 40.4 de la CDN, que establece que las sanciones impuestas a los niños acusados de infringir leyes penales deben asegurar el "bienestar" del joven y guardar proporción "tanto con sus circunstancias personales como con la infracción". Una norma muy similar está contenida en la regla $\mathrm{n}^{\circ} 5$ de las Reglas de Beijing. A ella debemos agregar la regla $\mathrm{n}^{\circ} 17.1$ a) que repite esta idea a propósito de regular los principios rectores de la sentencia. Finalmente, lo anterior se complementa con la regla $\mathrm{n}^{\circ} 16.1$ que establece que para facilitar la decisión del caso, la autoridad debe efectuar investigaciones completas sobre las circunstancias personales del niño. En este conjunto de normas se puede apreciar una clara vocación por considerar elementos para la determinación de las respuestas del sistema muy vinculados a las características personales del joven que es objeto de la persecución de parte del sistema. La idea es que la respuesta del sistema que surja como consecuencia de la valoración de dichas circunstancias cumpla con un objetivo de educar al joven para su vida en sociedad y no sea simplemente pura retribución. En consecuencia, buena parte del proceso juvenil no sólo gira en torno al establecimiento de los hechos que se imputan y de la participación del joven en ellos, elemento común con el proceso de adultos, sino que se refiere a la producción de información que permita tomar una decisión más acertada de cuál es la respuesta razonable en caso que efectivamente se determine su responsabilidad. Esta situación es la que caracterizo con el título de esta sección como un "énfasis en el joven" que exige el proceso juvenil para la toma de decisiones de parte de las autoridades.

El tema relevante para este estudio es determinar el cómo este elemento estructural del sistema penal juvenil debiera impactar en el diseño procesal. Nuevamente se trata de un área en donde la legislación internacional da amplio margen de apreciación a los Estados partes al no contemplar regulaciones específicas que impongan arreglos institucionales concretos en la materia. Tampoco se trata de un tema que aparezca comentado con especificidad por el Comité de Derechos del Niño más allá de los principios generales que ye he revisado. Con todo, con la idea de avanzar posibles consecuencias de esta lógica que me permitan en un próximo trabajo analizar el cómo el

\footnotetext{
110 OG/10 párrafo 71.

111 Idem.
} 
El derecho a un juzgamiento especializado de los jóvenes infractores en el derecho internacional de los derechos humanos y su impacto en el diseño del proceso penal juvenil.

derecho comparado y nacional se hacen cargo de este tema me parece posible sugerir tres derivaciones procesales al énfasis que impone el sistema internacional en el joven.

Una primera tiene que ver con la necesidad de reformular los sistemas de determinación de consecuencias o penas. En efecto, la regla general en el sistema de adultos en la tradición continental o inquisitiva ha sido la de concentrar en un mismo debate tanto los aspectos propios de la determinación de responsabilidad (esclarecimiento del hecho y la participación) como los vinculados a la individualización de la pena. Este diseño tiene un alto impacto en diversos aspectos procesales, pero como destaca Maier uno de los más relevantes es que ha relegado los ejercicios de individualización de la pena a cuestiones muy abstractas o formales. ${ }^{12}$ Para ponerlo de una forma un poco más gráfica, el debate principal sobre responsabilidad ha tendido a "engullirse" al debate sobre determinación de pena. Llevado esto al ámbito juvenil se traduce en que todos los mandatos de consideración especial del niño para determinar la sanción adecuada se transformen en una pura formalidad. Frente a esto, la solución que se ha planteado en el ámbito doctrinal ${ }^{113}$ y comparado ${ }^{114}$ en materia de proceso de adultos es avanzar a la división o cesura del debate en dos partes, una exclusivamente destinada al la discusión de la responsabilidad y otra a la determinación de consecuencias. ${ }^{115}$

En este contexto, me parece que un sistema nacional que quiera tomarse en serio las consecuencias que emanan de reglas internacionales revisadas en esta sección debiera pensar en algún diseño procesal que recoja la necesidad de tener un debate intenso y detallado de las condiciones particulares del joven infractor al momento de determinar la consecuencia aplicable. En este sentido, pero acotando los alcances de la cesura, Mary Beloff ha sostenido "También debe preverse la cesura del debate... de modo de diferenciar claramente la discusión en relación a la responsabilidad por el hecho, de la discusión en torno a la sanción o medida a aplicar, en donde las circunstancias personales y de mayor o menor vulnerabilidad del joven infractor sólo pueden operar como un correctivo que disminuya el reproche por el hecho". ${ }^{116}$

112 Véase Maier, "Los niños”, cit. nota n. 33, p. 382.

113 Sólo como ejemplo, en los procesos de reforma procesal penal en América Latina esta postura ha sido propuesta por sus impulsores originales. Además del texto de Maier ya citado puede ver la postura de Binder en Binder, Alberto, "Principios Fundamentales del Proceso penal Acusatorio", en Ideas y materiales para la reforma de la Justicia Penal, Editorial Ad-Hoc, Buenos Aires, 2000, p. 106.

114 La división o cesura del debate es un elemento presente por regla general desde antiguo en los sistemas procesal penales adversariales de tradición anglosajona. Así, por ejemplo, se ha sostenido a propósito de la tradición del common law que para ellas es “...hasta deseable, disociar la decisión acerca de culpabilidad, de la que se refiere a la pena.”. Véase Garapon, Antoine y Papadopoulos, Loannis, Juzgar en Estados Unidos y en Francia: Cultura jurídica Francesa y Common Law, Legis, Bogotá, 2006, p. 92

115 Un ejemplo muy concreto es lo que ha ocurrido con la regulación del artículo 343 del Código Procesal Penal Chileno, el que fue modificado en noviembre de 2005 con el objeto de reforzar la división obligatoria del debate en ciertas hipótesis. 
Frente a este desafío de diseño procesal existen diversos modelos y alternativas posibles en el ámbito comparado, cuestión sobre la que no iré en este trabajo.

Una segunda derivación relevante tiene que ver con las necesidades especiales de producción de información sobre el niño que es objeto de persecución penal, que precisamente le permitan al sistema hacer un ejercicio de individualización adecuado de la respuesta del sistema al caso concreto. Como ya se señalaba, este aspecto tiene incluso una manifestación normativa concreta en la regla $n^{\circ} 16.1$ de las Reglas de Beijing, como también en otras disposiciones internacionales. ${ }^{117} \mathrm{El}$ cumplimiento de esta regla impone algunas decisiones orgánicas, como por ejemplo si esa información se producirá por el mismo investigador (fiscal o policía) o es necesario establecer una agencia independiente que se haga cargo de ello. Pero también supone resolver una serie de aspectos de naturaleza procesal, vinculadas al resguardo de los derechos del niño en la obtención y presentación de esa información (por ejemplo relativos a su privacidad, al derecho a confrontar, etc.).

Un último impacto de carácter procesal, muy vinculado a los dos previos, debiera darse en materia de reglas de admisibilidad de evidencia. Si es cierto que en materia de responsabilidad juvenil los aspectos vinculados a la persona del niño infractor son muy decisivos para determinar las consecuencias que el sistema va a aplicar, más allá de la gravedad del hecho cometido, esto debiera flexibilizar algunas reglas de admisión de prueba pensadas para un contexto en donde dicha información suele no ser considerada. Así, por ejemplo, la regla de relevancia debiera naturalmente flexibilizarse (al menos para el debate de determinación de la pena) que llevaría naturalmente a excluir prueba en caso de los adultos cuando no está vinculada al hecho enjuiciado o recae sobre aspectos personales que no se pueden considerar en su caso. Algo similar podría potencialmente ocurrir con la admisión de peritajes que, tratándose de adultos, podrían ser considerados innecesarios. ${ }^{118}$

\section{5.- Tercer Eje: Política Amplia de Diversificación de Respuestas y Desestimación de Casos:}

Un tercer eje en donde el principio de especialidad tiene un impacto directo en materia procesal penal es en el establecimiento como elemento orientador del sistema de la idea que se debe evitar al máximo el contacto de los jóvenes con el mismo. De esta forma, los sistemas de responsabilidad de los jóvenes infractores deben establecer un conjunto de reglas que permitan

117 Un análisis más detallado de esta regla como asimismo de otras normas internacionales que establecen la misma lógica y la presentación de la respuesta normativa que ellas han tenido en varios de los nuevos sistemas juveniles en América Latina puede verse en Beloff, "Los Equipos", cit. nota n. 103, pp. 31 a 50.

118 Se trata de un tema que presenta muchos más complejidades y en el donde abordarlas podría llevar a perder el foco de este trabajo. En todo caso sugiero a quienes tengan interés en profundizar algunas de ellas ver Duce, Mauricio, La Prueba Pericial en los Procesos Orales, en Estudios de Homenaje a Raúl Tavolari, Lexis Nexis, Santiago, 2007, pp. 383 a 428. 
El derecho a un juzgamiento especializado de los jóvenes infractores en el derecho internacional de los derechos humanos y su impacto en el diseño del proceso penal juvenil.

la posibilidad de implementar políticas amplias de remisión (diversión y desestimación) de los casos antes que ingresen al proceso judicial formal y, en el evento que lo hagan, establecer facultades amplias a las diversas autoridades para poder prescindir de la persecución de responsabilidad de dichas infracciones.

Los principales fines buscados con esta lógica son evitar las consecuencias negativas que para un joven pueda producir su participación en un proceso judicial, incluyendo el potencial efecto estigmatizador del mismo. ${ }^{119}$ La idea detrás de esto es que debido a la mayor vulnerabilidad que se encuentran los jóvenes se entiende que un proceso formal en su contra tiene altas posibilidades de incidir negativamente en el desarrollo de los mismos y, por estas razones, se intenta reservar la utilización de este mecanismo sólo para casos en dónde no aparezcan mejores opciones para resolver el conflicto generado por la infracción.

Se trata de un área en donde hay una diferencia importante en relación a las reglas que regulan el procedimiento de adultos. Si bien la introducción de diversas facultades discrecionales y salidas alternativas (todas ellas agrupadas bajo la noción de "principio de oportunidad") se ha transformado en una característica común en las regulaciones procesales contemporáneas, lo cierto es que dichas facultades no forman parte de las exigencias contenidas en las normas internacionales y, además, los fines o fundamentos por las cuales se han introducido en las legislaciones de adultos difieren de los fines centrales perseguidos en materia de responsabilidad de los jóvenes infractores. ${ }^{120}$ Así, en el caso de las legislaciones procesales de adultos, al menos en los países de tradición continental, el principio de legalidad procesal sigue siendo la regla general de la persecución penal y la posibilidad de desestimar casos una excepción. Incluso se da el caso de varios países en América Latina en donde las excepciones a dicho principio son mínimas (por ejemplo en Ecuador o el Sistema Federal Argentino) y ello no es problemático desde el punto de vista de las normas internacionales de derechos humanos. En cuanto a los fines, a diferencia de los jóvenes, en los adultos en una porción importante estas instituciones no apuntan como eje central al beneficio imputado sino más bien a los efectos positivos para el sistema (vgr. descongestión del sistema).

Las diferencias descritas marcan una orientación distinta y muy específica de las normas internacionales especiales en la materia. Allí donde tratándose de adultos estas cuestiones no son objeto de regulación específica en los instrumentos internacionales generales, respecto de

\footnotetext{
119 En este sentido véase Comité de los Derechos del Niño OG/10 párrafo 25 y comentario a Regla nº 11 de las Reglas de Beijing.

120 Una visión general sobre la regulación de este tipo de instituciones en las legislaciones procesales penales de adultos en siete países de América Latina puede verse en Stippel, Jorg y Marchisio, Adrián (editores), Principio de Oportunidad y Salidas Alternativas al Juicio Oral en América Latina, Editorial Ad-Hoc, Buenos Aires, 2002. Sobre una visión más conceptual sobre este punto con referencia a la legislación chilena véase Duce y Riego, Proceso, cit. nota n. 39, pp. 177 a 216 y 283 a 354.
} 
los jóvenes y niños surgen variadas normas y reglas que intentan orientar a las legislaciones nacionales. A continuación revisaré como este eje ha sido reconocido en el ámbito internacional, primero revisando algunos aspectos generales y luego deteniéndome en las hipótesis específicas que se regulan.

\section{1.- Reconocimiento Internacional: Aspectos Generales}

A diferencia de lo que ocurre tratándose de las reglas procesales referidas a los adultos, las normas contenidas en diversos instrumentos internacionales son claras en el establecimiento de la lógica de evitar al máximo la judicialización de los procedimientos como una regla general del sistema. Así, el artículo 40.3 b) de la Convención enfatiza la idea que en la regulación de la especialidad de los procedimientos contra jóvenes infractores los Estados partes deben adoptar medidas que eviten procedimientos judiciales, pero siempre teniendo presente que en la aplicación de dichas medidas se respeten plenamente los derechos humanos y garantías legales de los jóvenes.

En la misma dirección, la Regla n ${ }^{\circ} 11$ de las Reglas de Beijing recomienda el uso de la discreción por parte de distintas autoridades para evitar que los casos ingresen al sistema judicial formal, bajo el nombre de "remisión de casos". Por su parte, La Regla n 6 de las Reglas de Beijing pone especial énfasis en permitir un uso amplio de facultades discrecionales en las distintas etapas del proceso, es decir, cuando el caso ya ha ingresado al sistema. Incluso el artículo 40.4 de la Convención también podría leerse en la línea de la necesidad de enfatizar uso de salidas alternativas en el proceso en la medida que no fuera interpretado exclusivamente como una norma que regula las sanciones a los jóvenes infractores, sino un catálogo de respuestas posibles del sistema aún sin juzgamiento y sentencia definitiva en contra de un joven infractor. Lo mismo la Directriz n 57 de las Directrices de Riad.

Como se puede observar, se trata de un amplio reconocimiento normativo de la idea de evitar al máximo el uso de procedimientos judiciales. Esto ha sido además reforzado por la interpretación que se ha dado a estas reglas por distintos organismos internacionales. El Comité de los Derechos del Niño ha señalado en la OG/10 respecto al artículo 40.3 de la Convención que "Teniendo en cuenta que la mayoría de los niños delincuentes sólo cometen delitos leves, deberán estar previstos de una serie de medidas que entrañen la supresión del procedimiento penal o de justicia de menores y la reorientación hacia servicios sustitutorios (sociales) (es decir, remisión de casos), que pueden y deben adoptarse en la mayoría de los casos". ${ }^{121}$ Con todo, el Comité agrega que no se trata de una obligación que se limita sólo tratándose de delitos leves o a menores infractores que cometan delito por primera vez, aun cuando se reconoce

$121 \quad$ OG/10 de abril de 2007, párrafo 24. 
El derecho a un juzgamiento especializado de los jóvenes infractores en el derecho internacional de los derechos humanos y su impacto en el diseño del proceso penal juvenil.

que estadísticamente se trata de las hipótesis que constituyen un mayor ingreso de casos en la mayoría de los países. ${ }^{122}$ Finalmente, el Comité reconoce que corresponde a los Estados decidir la naturaleza y el contenido exacto de las medidas que deben adoptarse para evitar los procesos judiciales ${ }^{123}$, manifestando especial preocupación por fijar algunos principios que debieran orientar el caso de las remisiones, cuyo análisis reservaré para más adelante.

La Corte Interamericana también se ha pronunciado en un sentido parecido señalando en su OC/17 que "...Las normas internacionales procuran excluir o reducir la "judicialización" de los problemas sociales que afectan a los niños, que pueden y deben ser resueltos, en muchos casos, con medidas de diverso carácter, al amparo del artículo 19 de la Convención Americana, pero sin alterar o disminuir los derechos de las personas. En este sentido, son plenamente admisibles los medios alternativos de solución de las controversias, que permitan la adopción de decisiones equitativas, siempre sin menoscabo de los derechos de las personas". ${ }^{24}$

Los comentarios que acompañan a las Reglas de Beijing también se orientan en un sentido bastante similar al expuesto. Así, el comentario a la regla $n^{\circ} 11$ refiriéndose la remisión señala que "Esta práctica sirve para mitigar los efectos negativos de la continuación del procedimiento en la administración de justicia de menores (por ejemplo, el estigma de la condena o la sentencia). En muchos casos la no intervención sería la mejor respuesta. Por ello la remisión desde el comienzo y sin envío a servicios sustitutorios (sociales) puede constituir la respuesta óptima." 125

\section{2.- Reconocimiento Internacional: distintas hipótesis}

Bajo esta lógica general la legislación internacional incluye básicamente dos situaciones diversas que es necesario distinguir ya que en cada una de ellas existen recomendaciones específicas para regularlas y aplicarlas.

La primera situación se refiere a la posibilidad de los distintos actores del sistema que tienen un primer contacto con el caso (normalmente la policía o los fiscales del Ministerio Público) de desestimarlo antes que se decida iniciar un proceso formal (intervención del juez en una vista formal) de persecución de la responsabilidad del joven infractor sin que exista ninguna condición asociada a tal desestimación. Esta posibilidad está prevista, por ejemplo, en la Regla $\mathrm{n}^{\circ} 11.2$ de las Reglas de Beijing. Se trata de una facultad asociada a la lógica de evaluación político criminal acerca de la inconveniencia de llevar adelante una persecución en una hipótesis en donde ella pueda provocar más daños que efectos positivos para el joven. A

Idem párrafo 25.

Idem párrafo 27.

OC/17-2002 párrafo 135 .

Reglas de Beijing comentario Regla n ${ }^{\circ} 11$. 
esta primera situación la identificaré como "remisión o desestimación no condicionada previa a la intervención judicial"

En cuanto se trata de una desestimación que no acarrea consecuencias para los jóvenes, la legislación internacional no manifiesta mucha preocupación acerca de la manera concreta en que debe ejercerse. La Regla ${ }^{\circ} 11.2$ de las Reglas de Beijing expresa la necesidad que el ejercicio de este tipo de facultades sea conforme a criterios establecidos en el sistema respectivo y sea ejercido en armonía con los principios establecidos en las propias Reglas. En este sentido una preocupación por el uso de este tipo de facultades es que ellas no sea objeto de discriminaciones de carácter arbitrario. Por ejemplo, sólo cuando se reserve su uso para un cierto perfil de jóvenes con mayor integración social. En consecuencia, las limitaciones que se imponen al uso de este tipo de facultades tienen que ver más bien con el hecho que ellas se utilicen ampliamente en favor de todo tipo de jóvenes y no con restricciones o cautelas que tiendan a disminuir su aplicación.

De manera consistente con la idea anterior, si bien la posibilidad de desestimación no condicionada parece hacerse naturalmente operativa en casos menores o de infractores primerizos, tanto el Comité en su OG/10 que hemos citado como los comentarios de las Reglas de Beijing incentivan a que se ocupen en otros tipos de casos, lo que podría marcar una diferencia con reglas de oportunidad contenidas normalmente a favor de adultos que suelen referirse exclusivamente a hechos menores ${ }^{126}$ o que en muchas ocasiones imponen condiciones como la reparación para su procedencia. ${ }^{127}$ En consecuencia, a nivel de legislaciones internas esto debiera reflejarse en una mayor amplitud en el uso de estos mecanismos que tratándose de los adultos, ya sea por incluir más casos o por eliminar algunas de las barreras o exigencias que se imponen como condiciones previas para su uso.

Una segunda hipótesis que es posible identificar en la legislación internacional se refiere a lo que propiamente los tratados internacionales denominan "remisión". Es decir, los casos en que se decide, aún antes de iniciar un procedimiento formal, no llevar el caso adelante pero enviándolo algún tipo de servicio sustitutorio o a alguna medida para el tratamiento del joven infractor. Esta situación podría identificarse como casos de "remisión o desestimación con medidas o condiciones antes de la intervención judicial". En esta segunda hipótesis las autoridades encargadas de decidir si se lleva adelante la persecución formal de la infracción prefieren un sistema alternativo de resolución del conflicto al sistema judicial formal que podría implicar algún tipo de restricción de derechos del joven imputado.

\footnotetext{
126 Por ejemplo lo regulado en el artículo 170 del Código Procesal Penal de Chile en donde sólo es procedente la oportunidad en el evento que la pena mínima asignada al delito imputado no exceda el primer tramo de privación de libertad previsto en el Código Penal (61 a 540 días).

127 Por ejemplo lo regulado en el artículo 2.2 del Código Procesal Peruano de 2004.
} 
El derecho a un juzgamiento especializado de los jóvenes infractores en el derecho internacional de los derechos humanos y su impacto en el diseño del proceso penal juvenil.

En estos casos, derivado precisamente de las consecuencias que la remisión puede generar, el sistema internacional ha formulado mayores precisiones y recomendaciones acerca de cómo deben regularse y cómo debe aplicarse por los Estados. Estas preocupaciones se traducen naturalmente en limitar la procedencia de estas medidas a los supuestos en donde se den todas las condiciones establecidas en el sistema internacional. Normativamente esta mayor preocupación esta reflejada en al propia Convención al manifestar en su artículo 40.3 b) que la remisión es preferible al proceso formal en el entendió que "se respetarán plenamente los derechos humanos y las garantías legales" de los jóvenes. Esto ha sido materia de especial preocupación por parte del Comité de los Derechos del Niño y así se reflejó en su OG/10 en donde se establecen cinco elementos a considerar por los Estados partes para hacer uso de la remisión que a continuación resumo: ${ }^{128}$

- Sólo debe utilizarse cuando existen pruebas fehacientes que el niño ha cometido el delito que se imputa;

- $\quad$ El niño debe admitir libre y voluntariamente su responsabilidad (sin intimidación o presión y sin que la admisión pueda ser utilizada en un procedimiento legal ulterior).

- El niño debe prestar su consentimiento libre y voluntariamente por escrito a la remisión del caso. El consentimiento debe basarse en información adecuada y específica sobre la naturaleza, contenido, duración y consecuencias de las medidas. Se considera, además, en caso de menores de 16 años, la posibilidad que los padres deban prestar también el consentimiento.

- $\quad$ El legislador debe regular las hipótesis de procedencia como también las facultades de las autoridades encargadas de su aplicación con objeto de proteger al niño de cualquier tipo de discriminación.

- $\quad$ La remisión debe suponer el cierre definitivo del caso, admitiéndose la mantención temporal y con fines limitados de un sistema de registro de la misma.

Esta mayor preocupación también está contenida en las Reglas de Beijing. Así, la Regla $\mathrm{n}^{\mathrm{o}} 11.3$ exige el consentimiento del menor o de sus padres o su tutor para su procedencia y la posibilidad que la decisión de remisión sea sometida al examen de una autoridad competente si así se solicita. El comentario a dicha regla enfatiza la necesidad que la validez del consentimiento sea impugnable, frente a la posibilidad que haya sido entregado por "pura desesperación" o como producto de presiones o coerción. En el mismo sentido la doctrina también ha manifestado la idea que consentimiento y asistencia letrada del joven constituyen elementos claves para no afectar sus garantías básicas. ${ }^{129}$

Me parece posible también distinguir una tercera hipótesis o situación en donde la lógica

128

129
OG/10 2007, párrafo 27.

Véase Beloff, "Los Nuevos", cit. nota n. 9, p. 47. 
general que se revisa podría aplicarse. Se trata de los casos en donde una vez iniciada formalmente la persecución de la responsabilidad de un joven infractor, se decida, en sede judicial, remitir el caso a un sistema alternativo o desestimarlo. Esta tercera situación podría ser identificada como "remisión o desestimación una vez producida la intervención judicial".

Como hemos visto, en general las normas internacionales y las opiniones de los órganos que las interpretan se han preocupado de regular con mayor especificidad los casos en que la remisión se articula antes de la intervención formal del sistema. Esto es lógico ya que en dicha hipótesis la remisión satisface de mejor forma su objetivo de evitar los efectos negativos que produce el contacto del joven con el mismo. Con todo, me parece que el mandato general de los instrumentos internacionales también incluye una orientación a sacar del sistema a los casos que por diversos motivos no han sido desestimados o remitidos antes que ingresen a la justicia formal. ${ }^{130} \mathrm{El}$ tratamiento que debieran tener los casos en esta hipótesis debiera asociarse a situación más análoga, es decir, si se trata de una remisión o desestimación.

Se puede apreciar que en las hipótesis que como consecuencia de la desestimación o remisión surgen condiciones que restringen o limitan la libertad del joven imputado, la legislación internacional establece parámetros bastante estrictos para su procedencia. Una clara preocupación detrás de estas exigencias es evitar el riesgo que por vía de estos sistemas de condiciones, lejos de producirse una disminución del control social se genere su ampliación. Tal como lo ha señalado la doctrina, que por esta vía se llegue a tener "redes distintas, más amplias y sutiles". ${ }^{131}$ Así, entonces, se puede apreciar que el Comité exige que se utilicen estas remisiones condicionadas sólo cuando exista prueba fehaciente del delito que se imputa y admisión de responsabilidad del joven, exigencias que normalmente no se encuentran presentes en instituciones equivalentes de adultos. Veamos esto con un poco más de detalle y con un ejemplo concreto que ayude a comprender mejor esta idea.

Una de las instituciones que se ha introducido con mayor fuerza en las nuevas legislaciones procesales penales de adultos en la región (pero también a nivel comparado) que puede considerarse claramente un caso paradigmático de desestimación condicionada es la llamada suspensión condicional del procedimiento o suspensión del juicio a prueba. ${ }^{132}$ En general, se trata de una salida alternativa al proceso que permite su suspensión, previo acuerdo entre fiscal e imputado, bajo un régimen temporal de cumplimiento de condiciones. Al revisarse la mayoría de las legislaciones de América Latina que la han contemplado se puede apreciar que

\footnotetext{
130 En este sentido véase las opiniones del Comité de Derechos del Niño en su OG/10 párrafo 68.

131 Véase Llobet, cit. nota n. 40, p. 23 nota a pié de página 76.

132 Una revisión general sobre la regulación a nivel regional puede verse en Stippel y Marchisio, Principio, cit. nota n. 122. Para una revisión general en el contexto europeo véase Albrecht, Hans Jôrg, Settlements Out of Court: A Comparative Study of European Criminal Justice Systems, Research Paper n ${ }^{\circ}$ 19, SouthAfrican Law Comisión.
} 
El derecho a un juzgamiento especializado de los jóvenes infractores en el derecho internacional de los derechos humanos y su impacto en el diseño del proceso penal juvenil.

normalmente para su uso no se exige ni reconocimiento de responsabilidad por parte del imputado ni la existencia de pruebas fehacientes al Ministerio Público que el imputado ha cometido el delito. La no existencia de estas dos exigencias marca una clara diferencia en la concepción de estas instituciones en adultos y jóvenes. A partir de la falta de ellas es posible que un fiscal intente utilizar esta institución en vez de llevar adelante una persecución penal no por consideraciones en favor del imputado sino principalmente como una forma de articular una respuesta del sistema en un caso débil en donde estime que en el evento de llegar a juicio no va a tener posibilidades de obtener una condena. Para el imputado, en cambio, no obstante se sostenga la inocencia, es posible acordar una suspensión si es que estima que a pesar de ser inocente esta salida alternativa le significa un menor riesgo que ir a un juicio oral. Ambos tipos de situaciones estarían prohibidas de acuerdo a las exigencias establecidas por el Comité tratándose de los jóvenes. Con ello se pretende evitar que un joven no responsable en un caso sin fundamentos serios sea sometido a condiciones restrictivas que podrían no imponerse en el evento que dicho caso se juzgara formalmente por el sistema. Ello representaría una ampliación de la intervención del sistema allí donde precisamente lo que se busca es evitar al máximo la intervención de éste.

Además de estas restricciones, las Reglas de Beijing, como ya mencioné, ponen especial acento en la voluntariedad real del consentimiento otorgado por el joven a una medida de esta naturaleza. Si bien la voluntariedad también representa una preocupación en el caso de adultos, el hecho que intervenga un padre o tutor en su entrega marca una diferencia de importancia que tendrá impacto en diversas instituciones del proceso juvenil, ya que se asume que por el estado de desarrollo de algunos niños o jóvenes se requiere reforzar su capacidad de análisis y decisión con la intervención de adultos que le ayuden a comprender mejor las distintas cuestiones que se ponen en juego al momento de aceptar una medida como la remisión.

Finalmente, para concluir la revisión sobre este punto, es necesario señalar que en el ámbito internacional, ni los tratados internacionales ni los comentarios u observaciones de sus intérpretes, se ha avanzado en establecer el tipo de instituciones concretas de desestimación o remisión que deben regularse en las legislaciones internas como tampoco las hipótesis específicas en las que debieran utilizarse dichos mecanismos. Esto es una materia que, en opinión del Comité de los Derechos del Niño, cuya definición concreta debe quedar en mano de los Estados, no obstante se les recomienda beneficiarse de la experiencia desarrollada por varios países en la materia. ${ }^{133}$ La Regla ${ }^{\circ} 11.4$ de las Reglas de Beijing también establece que, para facilitar la remisión, se deba promover en la comunidad la existencia de programas de supervisión y orientación temporales, restitución y compensación de las víctimas. En cuanto a las hipótesis de procedencia, ya he señalado que, tanto el Comité en su OG/10 como en los comentarios de

133 Véase OG/10 2007 párrafo 27. 
las Reglas de Beijing, se recomienda su utilización no sólo en los casos leves y de primeras infracciones, sino también en caso más graves con el objetivo de transformar a estos mecanismos en herramientas importantes del sistema.

\section{6.- Consideraciones Finales.}

Durante el desarrollo de este trabajo se ha podido observar que el derecho internacional de los derechos humanos contiene una amplia gama de disposiciones que regulan aspectos del derecho del joven a ser juzgado en un sistema especializado. Varias de estas cuestiones han sido desarrolladas con cierto detalle por la jurisprudencia internacional o han sido objeto de comentarios por parte de los organismos responsables de su supervisión, lo que permite traducir los alcances de dichos mandatos en obligaciones bastante específicas para los Estados partes. Con todo, también hemos visto que muchas de ellas se plantean como principios generales entregándose un amplio margen de apreciación a los Estados para establecer normas y prácticas a nivel interno consistentes con dichos principios.

Me parece que evaluadas en su conjunto, las derivaciones del principio de especialidad en materia procesal establecen altas exigencias a las legislaciones nacionales que obligan a repensar de una manera profunda los diseños y estructuras procesales que tradicionalmente se han contemplado para los adultos. En este contexto, el desafío para los próximos capítulos de esta investigación será establecer cuánto se ha avanzado en esto en el derecho comparado y ver qué es lo que ha ocurrido a dos años de implementación del nuevo sistema de responsabilidad juvenil en nuestro país. 
El derecho a un juzgamiento especializado de los jóvenes infractores en el derecho internacional de los derechos humanos y su impacto en el diseño del proceso penal juvenil. 